\title{
Pro-invasive properties of Snail1 are regulated by sumoylation in response to TGF $\beta$ stimulation in cancer
}

\author{
Shyam Kumar Gudey ${ }^{1, *}$, Reshma Sundar ${ }^{1, *}$, Carl-Henrik Heldin², Anders Bergh ${ }^{1}$ \\ and Marene Landström ${ }^{1}$ \\ ${ }^{1}$ Department of Medical Biosciences, Umeå University, Umeå, Sweden \\ ${ }^{2}$ Ludwig Institute for Cancer Research, Science for Life Laboratory, Uppsala University, Uppsala, Sweden \\ * These authors have contributed equally to this work
}

Correspondence to: Marene Landström, email: Marene.Landstrom@medbio.umu.se

Keywords: signal transduction, tumor biology, Snail 1, sumoylation, prostate cancer

Received: March 03, 2017

Accepted: May 19, 2017

Published: August 09, 2017

Copyright: Gudey et al. This is an open-access article distributed under the terms of the Creative Commons Attribution License 3.0 (CC BY 3.0), which permits unrestricted use, distribution, and reproduction in any medium, provided the original author and source are credited.

\section{ABSTRACT}

Transforming growth factor $\beta$ (TGF $\beta$ ) is a key regulator of epithelial-tomesenchymal transition (EMT) during embryogenesis and in tumors. The effect of TGF $\beta$, on EMT, is conveyed by induction of the pro-invasive transcription factor Snail1. In this study, we report that TGF $\beta$ stimulates Snail1 sumoylation in aggressive prostate, breast and lung cancer cells. Sumoylation of Snail1 lysine residue 234 confers its transcriptional activity, inducing the expression of classical EMT genes, as well as TGF $\beta$ receptor I (T $\beta R I$ ) and the transcriptional repressor Hes1. Mutation of Snail1 lysine residue 234 to arginine (K234R) abolished sumoylation of Snail1, as well as its migratory and invasive properties in human prostate cancer cells. An increased immunohistochemical expression of Snail1, Sumo1, TRRI, Hes1, and c-Jun was observed in aggressive prostate cancer tissues, consistent with their functional roles in tumorigenesis.

\section{INTRODUCTION}

Transforming growth factor beta (TGF $\beta)$ is a versatile cytokine implicated in crucial cellular processes such as embryogenesis, differentiation, proliferation, apoptosis, and tissue repair $[1,2]$. TGF $\beta$ was discovered in 1980 and was originally given its name because of its ability to promote anchorange-independent growth of rat fibroblasts. In contrast, TGF $\beta$ was later found to inhibit proliferation of epithelial cells and maintain their homeostasis; Thus TGF $\beta$ has both pro-tumorigenic and tumor suppressive effects [1,3-5]. TGF $\beta$ exhibits its growth-suppressive effects at initial stages by limiting cell proliferation and cell migration, and inducing apoptosis in normal epithelial cells $[6,7]$. At later stages, however, TGF $\beta$ promotes tumor growth by evading these inhibitory signals and instead triggering other cellular processes such as the epithelial-to-mesenchymal transition (EMT), enabling cells to become motile and traverse to distant organs and metastasize $[6,8]$.
TGF $\beta$ signals by forming a heterotetrameric complex of two types of serine/threonine receptor kinases, the TGF $\beta$ receptors (T $\beta$ Rs) II and I [9]. Ligand binding to the T $\beta R$ complex activates the T $\beta R I$ kinase, which phosphorylates the receptor-associated Smads (R-Smads) 2 and 3, at their extreme C-terminal motifs, allowing them to form complexes with the co-Smad, Smad 4 [10-12]. The trimeric Smad complexes then translocate to the nucleus and promote TGF $\beta$-induced transcriptional responses by binding to the Smad Binding Elements (SBEs) composed of the sequence CAGACA on the DNA $[13,14]$.

Intriguingly, TGF $\beta$ also drives transcriptional responses through other signaling pathways, referred to as non-Smad signaling, e.g. via ERK, JNK, and p38 mitogen activated protein kinases (MAPK) $[7,15,16]$. In this context, our group has identified that the E3 ligase tumor necrosis factor receptor (TNFR) associated factor 6 (TRAF6) plays a pivotal role in non-Smad signaling pathways [17]. TGF $\beta$ induced oligomerization of T $\beta$ RIIT $\beta$ RI complex promotes auto-ubiquitination of TRAF6 
and subsequent activation of the TAK1-MKK3/6-p38MAPK pathway [17-19]. TRAF6 also promotes cleavage of T $\beta$ RI by activating the proteolytic proteases TACE (TNF- $\alpha$ converting enzyme), known as ADAM17, and presenilin1, in the ecto- and transmembrane regions, respectively $[20,21]$. The cleaved T $\beta R I$-intracellular domain (T $\beta R I-I C D)$ translocates to the nucleus where it binds to the transcription regulator p300 and activates proinvasive genes, such as Snail1 and MMP2 [22].

One of the hallmarks of the EMT process is the repression of epithelial markers, such as E-cadherin and occludin, and upregulation of mesenchymal markers such as vimentin, N-cadherin, and fibronectin1[23]. Key transcriptional regulators, such as Snail1, Twist1, Zeb1, and Slug play pivotal roles in this process [24].

TGF $\beta$ is well known to drive the EMT process by inducing the expression of Snaill and other transcription factors, thereby regulating the expression of crucial mesenchymal markers [25] [26]. Interaction between signaling components of the TGF $\beta$ family and Snail 1 has been reported. Smad3 and Smad4 form a complex with Snail1, driving EMT in breast carcinomas [27]. The high mobility group A2 (HMGA2) protein directly binds to the Snaill promoter and acts as a transcriptional regulator of Snail1 expression [28]. Snaill has also been reported to bind to its own promoter and regulate its own expression [29]. Previously, we have reported that the AP-1 transcription factor $c$-Jun binds to a distal region of the Snaill promoter and thereby promotes invasion of prostate cancer cells [30, 31].

Moreover, various post-translational modifications regulate the stability and activity of Snaill protein expression. For instance, Snaill has been reported to undergo polyubiquitination in the nucleus by F-box protein FBXL5, thereby hampering Snaill ability to bind to DNA [32]. Sumoylation i.e. the conjugation of a small ubiquitin-like modifier (SUMO) to the target substrate, regulates protein stability, nucleo-cytoplasmic shuttling, active gene transcription, chromosome organization and DNA repair [33]. Conjugation of sumo moieties to the target lysine residue occurs either by monoSUMOylation or by attachment of SUMO chains (polySUMOylation) $[34,35]$.

Although it has been reported that there is crosstalk between Smads and Snail1, it is still unclear which downstream targets of Snaill promote EMT in TGF $\beta$ stimulated cells. In this study, we explored the downstream regulators of Snail1, and found that Snail 1 regulates both mRNA and protein expression of T $\beta R I$ and the transcriptional repressor Hes1. Moreover, we observe that knockdown of the T $\beta$ RI decreases the expression of Hes 1 and EMT-related genes. We also found that TGF $\beta$ promotes sumoylation of Snail1. Moreover, mutagenesis of Snail1 lysine residue 234 to arginine (K234R) abolished sumoylation of Snail1, its transcriptional activity, and migration and invasion of prostate cancer cells.

\section{RESULTS}

\section{Snail1 regulates T $\beta R I$ expression}

To investigate whether Snaill regulates the expression of T $\beta$ RI, we silenced the endogenous expression of Snaill by using siRNA or non-targeting control siRNA in PC-3U cells and probed with antibodies directed against T $\beta$ RI. Downregulation of Snail1 expression by siRNA\#1 or siRNA\#2 decreased T $\beta$ RI protein (T $\beta R I)$ expression (Figure 1A and Supplementary Figure 1A). Moreover, silencing of Snaill decreased T $\beta R I$ mRNA expression, as determined by RT-PCR analysis (Figure 1B). Downregulation of Snaill expression was confirmed at both the protein and mRNA levels (Figure 1A, 1C, and Supplementary Figure 1A). Because R-Smads (Smad2, Smad3) are the downstream regulators of T $\beta$ RI, we investigated the effects of silencing of Snail1, on the phosphorylation of Smad2 by using phospho-specific antibodies; treatment with siSnail1 reduced the phosphorylation of $\mathrm{Smad} 2$ (Figure 1A). Moreover, the mRNA expression of the TGF $\beta$ target gene Smad7 also decreased in the absence of Snail1 (Figure 1D). As downregulation of endogenous Snail1 expression decreased phosphorylation of Smad2, we investigated if the downregulation of T $\beta$ RI by Snail1, inhibits Smads to bind to the Smad Binding Elements (SBEs) by performing Smad-specific promoter reporter assays by transfecting $\mathrm{CAGA}_{12}$-Luc reporters in siCtrl or siSnail1 treated PC-3U cells. Treatment with TGF $\beta$ for $24 \mathrm{~h}$ significantly enhanced $\mathrm{CAGA}_{12}$-Luc reporter activity in siCtrl treated cells compared to siSnaill treated cells (Figure 1E). Next, we confirmed our findings that Snaill downregulates T $\beta$ RI protein expression in Snail1deficient mouse embryo fibroblasts (MEFs). The TGF $\beta$ enhanced expression of T $\beta$ RI protein expression observed in Snail1 $^{+/+}$MEFs was suppressed in Snail1/- MEFs (Figure 1F). Probing with phospho-Smad2 antiserum confirmed that T $\beta$ RI stimulation caused phosphorylation of Smad2 only in Snail1 ${ }^{+/+}$MEFs, but not in Snail1 ${ }^{-/-}$ MEFs (Figure 1F). Moreover, re-introduction of HASnail1 in Snail1 $1^{-/}$MEFs partially rescued the expression of T $\beta R I$ and phosphorylation of Smad2 (Figure 1F). By confocal imaging we observed that TGF $\beta$ stimulation of cells, enhanced the intensity and co-localization of T $\beta$ RI and Snail1 in siCtrl treated cells but not in siSnail1 treated cells (Supplementary Figure 2A). We confirmed our findings in Snaill deficient MEFs; whereas TGF $\beta$ treatment greatly enhanced the co-localisation of T $\beta R I$ and Snaill in Snail1 ${ }^{+/+}$MEFs, this was not seen in Snail1 ${ }^{-/}$ MEFs (Supplementary Figure 2B). These results suggest that Snaill enhances both mRNA and protein expression of T $\beta$ RI. 


\section{Snail1 interacts with T $\beta R I$}

Having observed that Snaill regulates T $\beta R I$, we investigated if Snaill forms a complex with TRRI in PC-3U cells. Interestingly, TGF $\beta$ induced a transient coimmunoprecipitation of endogenous Snaill with T $\beta R I-$ intracellular domain (TRRI-ICD) upon TGF $\beta$ stimulation (Figure 2A). By using proximity ligation assays (PLA), we confirmed that TGF $\beta$ treatment enhances Snail1T $\beta R I$ interaction in PC-3U cells (Figure 2B) and also in the highly invasive human breast cancer cell line MDAMB-231 (Supplementary Figure 3). Moreover, confocal imaging showed that TGF $\beta$ stimulates co-localization between Snaill and T $\beta R I$ in the nuclear compartment in PC-3U cells (Figure 2C). These results suggest that TGF $\beta$ promotes interaction of T $\beta R I$ and Snaill, in aggressive prostate and breast cancer cells.

To further investigate the interaction between Snaill and T $\beta R I$, we ectopically co-expressed GFPtagged TRRI and HA-Snaill in PC-3U cells. As expected, TGF $\beta$ stimulated an interaction between GFP-T $\beta R I$ and HA-Snail1 (Supplementary Figure 4A). Using confocal imaging, we observed that TGF $\beta$ stimulation promoted the co-localization of GFP-T $\beta R I$ and HA-Snail1 in the nuclear compartment, although a small amount of proteins co-localized also in the cytoplasm (Supplementary Figure 4B). Next, we ectopically co-expressed Flag-tagged T $\beta R I$ and HA-Snaill in PC-3U cells; consistent with our previous finding, we observed TGF $\beta$-dependent interaction between Flag-T $\beta$ RI-ICD and HA-Snail1, further confirming that TGF $\beta$ stimulates complex formation between TRRI-ICD and Snaill (Supplementary Figure $4 C$ ). Taken together, these results suggest that Snaill forms a complex with T $\beta R I-I C D$, in the nucleus of TGF $\beta$-treated prostate and breast cancer.

\section{Snail1 promotes EMT genes.}

Because Snail 1 has been implicated as a major contributor to the EMT process, we performed qRT-PCR experiments to investigate if the mesenchymal genes are regulated by Snail1 in response to TGF $\beta$. TGF $\beta$ triggered a Snail1-dependent upregulation of Fibronectin1, $N$-cadherin, and the Notch responsive gene Jagged 1 (Supplementary Figure 5A-5C). Moreover, Snail1 downregulation decreased the expression of other EMT regulators such as Zeb1, Slug, and Twistl (Supplementary Figure 5D-5F).

\section{Snail1 regulates Hes1 expression}

Hairy and enhancer of split-1 (Hes1) is an important transcriptional co-repressor implicated in Notch signaling. Interestingly, Hes1 has also been reported to play crucial role in EMT [38]. To investigate if Snaill regulates
Hes1 expression, we next silenced endogenous Snaill expression by siRNA\#1 or siRNA\#2 and probed with antibodies specific to Hes1. Silencing Snaill expression decreased Hes1 expression, suggesting that Snaill enhances Hes 1 expression (Figure 3A and Supplementary Figure 1A). qRT-PCR experiments confirmed that Hes 1 mRNA expression decreased in siSnaill treated cells compared to siCtrl treated cells (Figure 3B). Moreover, we found that overexpression of HA-Snail1, or TGF $\beta$ stimulation of PC-3U cells, enhanced the expression of the transcriptional repressor Hes1 (Supplementary Figure 6A). Also, re-introduction of HA-Snail1 in Snail1 ${ }^{-1-}$ MEFs rescued the expression of Hes1 (Figure 3C). Co-immunoprecipitation experiments further showed that TGF $\beta$ treatment for $1 \mathrm{~h}$ induced an interaction between endogenous Snaill and Hes1 (Figure 3D). Confocal imaging of PC-3U cells treated with TGF $\beta$ for $1 \mathrm{~h}$, revealed a co-localization of endogenous Hes1 and Snaill (Figure 3E) Moreover, a PLA showed that TGF $\beta$ stimulation of cells significantly increased Hes1-Snail1 complexes in the nucleus (Figure 3F). These results suggest that Snail1 regulates Hes1 expression and that Snail1 interacts with Hes 1 in the nucleus after $1 \mathrm{~h}$ of TGF $\beta$ treatment.

\section{Overexpression of HA-Snail1 promotes T $\beta R I$ expression}

To further evaluate our finding that Snaill regulates T $\beta$ RI expression, we overexpressed HA-Snaill at increasing concentrations and investigated the amount of TRRI protein by immunoblotting with antibodies against T $\beta$ RI. HA-Snaill overexpression at increasing concentrations enhanced expression of TRRI-FL and also TRRI-ICD expression upon TGF $\beta$ stimulation (Supplementary Figure 6B). qRT-PCR data revealed that overexpression of HA-Snaill or TGF $\beta$ stimulation of PC-3U cells, enhanced mRNA expression of T $\beta R I$ (Supplementary Figure 6C).

The qRT-PCR data also supported the finding that TGF $\beta$ stimulation enhanced the mRNA expression of Hes1 at increasing concentrations of HA-Snail1 overexpression; however, at $6 \mu \mathrm{g}$ concentration TGF $\beta$ stimulation decreased expression of T $\beta R I$ and did not affect Hes1 expression (Supplementary Figure 6C, D). As expected, TGF $\beta$ stimulation enhanced the Snail1 mRNA expression (Supplementary Figure 6E).

\section{T $\beta R I$ induces Hes1 expression}

We reported previously that T $\beta$ RI-ICD translocates to the nucleus, where it binds to the Snail1 promoter [20]. To further explore other co-transcriptional targets regulated by T $\beta R I-I C D$, we silenced T $\beta R I$ expression by siRNA and investigated the effect on the Notch responsive 
gene Hes1. Silencing T $\beta R I$ expression decreased the expression of Hes 1 giving further evidence that Hes 1 is a T $\beta R$ I responsive gene (Figure 4A). qRT-PCR experiments confirmed that downregulation of T $\beta R I$ in PC-3U cells significantly decreased Hes 1 mRNA expression (Figure 4B, 4C). Moreover, treatment of PC-3U cells with siRNA specific for endogenous T $\beta \mathrm{RI}$, decreased Hes 1 expression as visualized by confocal imaging (Figure 4D).
A
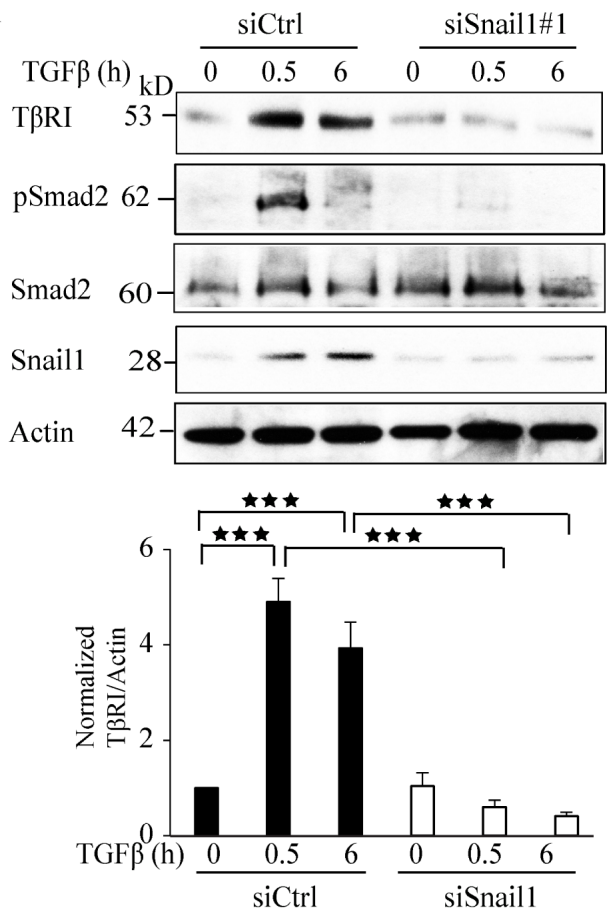

B

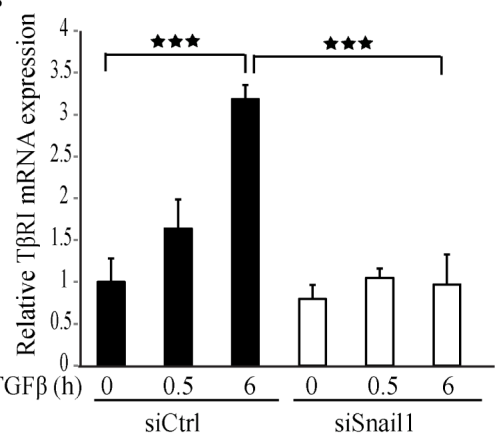

D

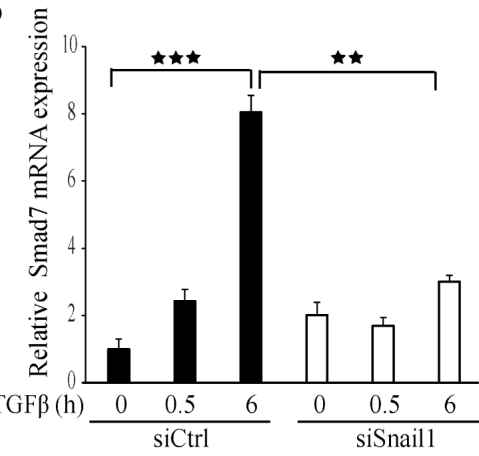

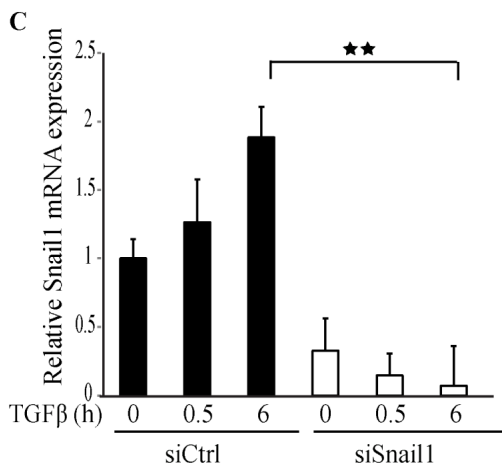

$\mathbf{E}$

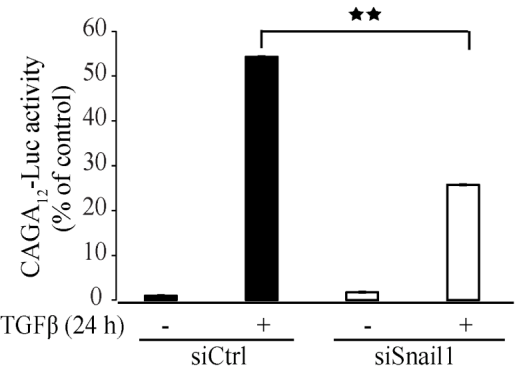

F
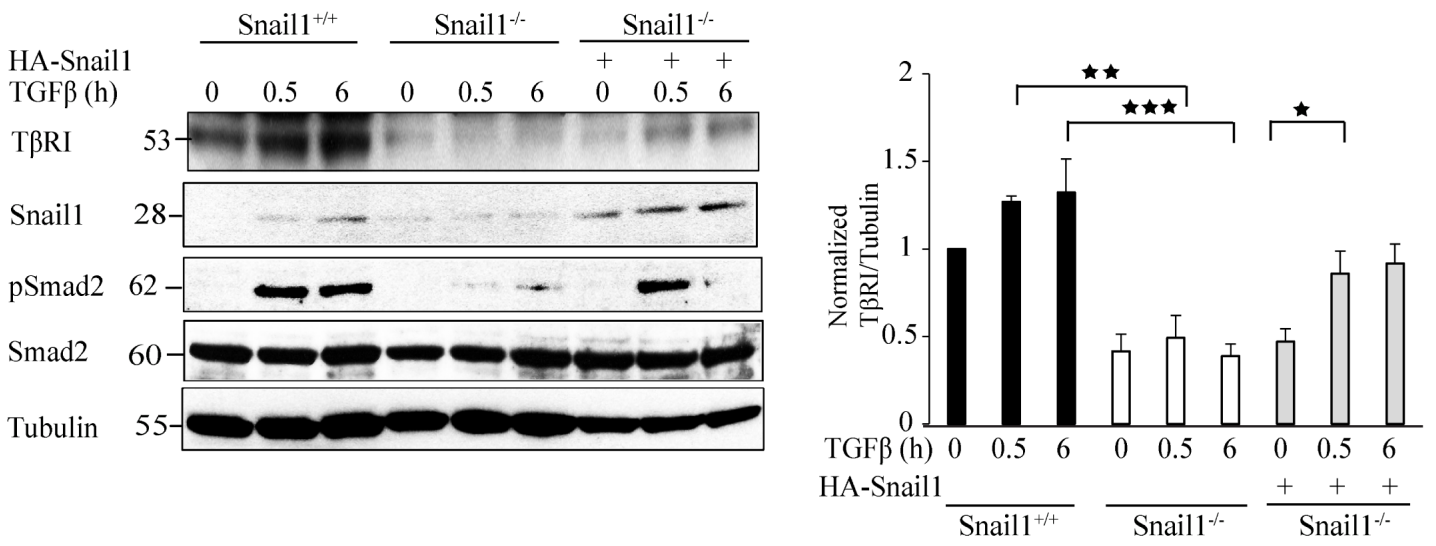

Figure 1: Snail1 regulates T $\beta$ RI expression. A. PC-3U cells were transiently transfected with control (Ctrl) or Snaill-specific siRNA \#1 and treated with TGF $\beta(10 \mathrm{ng} / \mathrm{ml})$ for the indicated time periods. Cell lysates were prepared and immunoblots were probed for T $\beta$ RI (T $\beta$ RI-FL), pSmad2, and Smad2, Snail1, and $\beta$-actin, which served as control for equal loading of proteins ( $n=5$ independent experiments). B.-D. qRT-PCR analysis of PC-3U cells transiently transfected with control (Ctrl) or Snaill-specific siRNA \#1 and treated with TGF $\beta(10 \mathrm{ng} / \mathrm{ml})$ as indicated. RNA was extracted and cDNA was prepared and used for qRT-PCR analysis of mRNA expression of T $\beta R I$, Snail1, and Smad7 respectively ( $n=4$ independent experiments). E. PC-3U cells were transiently transfected with control (Ctrl) or Snaill-specific siRNA \#1 followed by transfection of $\mathrm{CAGA}_{12}$-Luc reporter. Later, cells were starved and treated without or with TGF $\beta$ $(10 \mathrm{ng} / \mathrm{ml})$ for $24 \mathrm{~h}$ and luciferase activity was measured. ( $n=5$ independent experiments). F. Snail1 ${ }^{+/+}$, Snail1 ${ }^{-/}$MEFs, and Snail1 ${ }^{-/-}$MEFs transiently transfected with HA-Snaill were serum starved and treated with TGF $\beta$ for the indicated time periods. Cell lysates were prepared and immunoblots were probed for T $\beta$ RI (T $\beta$ RI-FL), Snail1, pSmad2, and Smad2, $\beta$-tubulin ( $n=4$ independent experiments). Bar graphs show the means \pm SEM; ${ }^{*} P<0.05,{ }^{* *} P<0.005,{ }^{* * *} P<0.0005$. Differences in the means \pm SEM between samples were analyzed with twoway ANOVA and Bonferroni correction for multiple comparisons. 
A
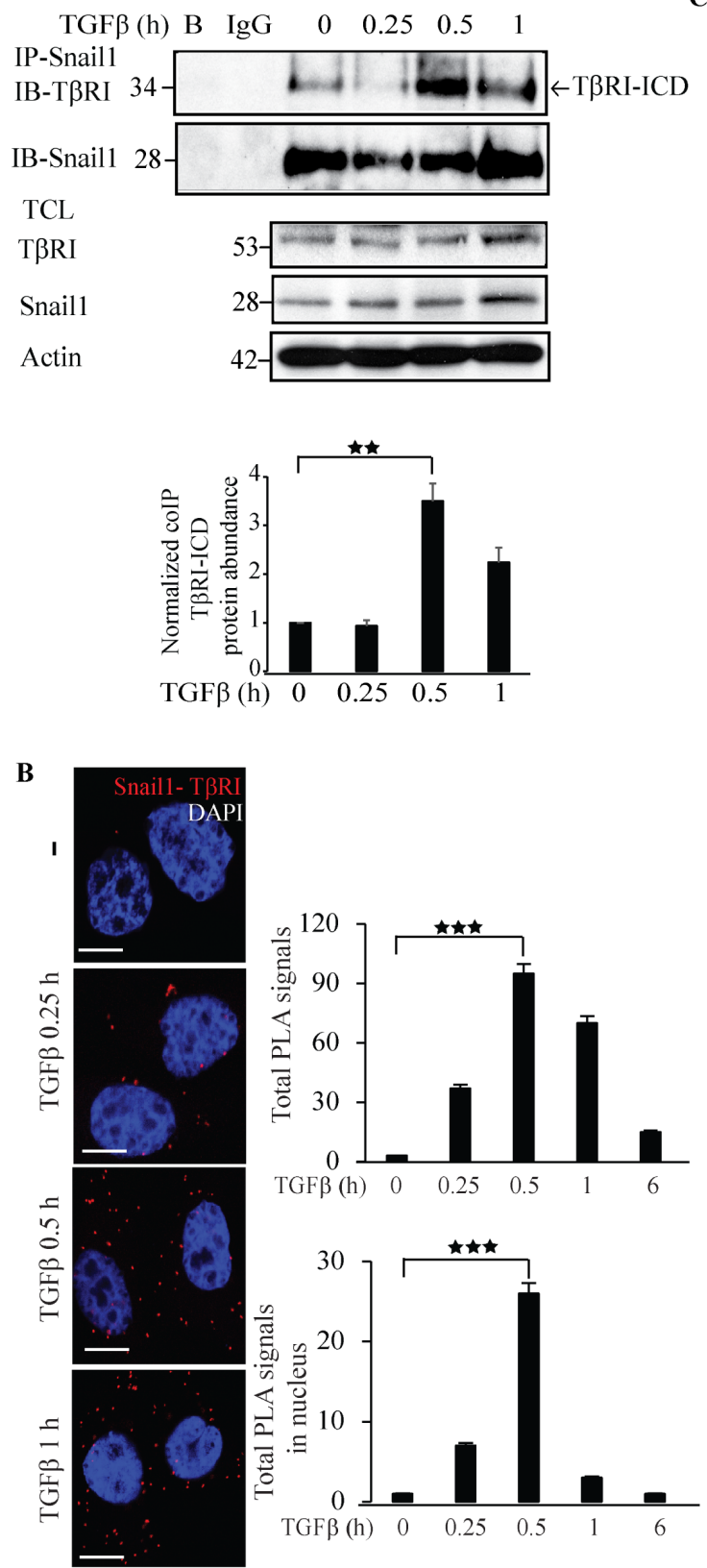

C

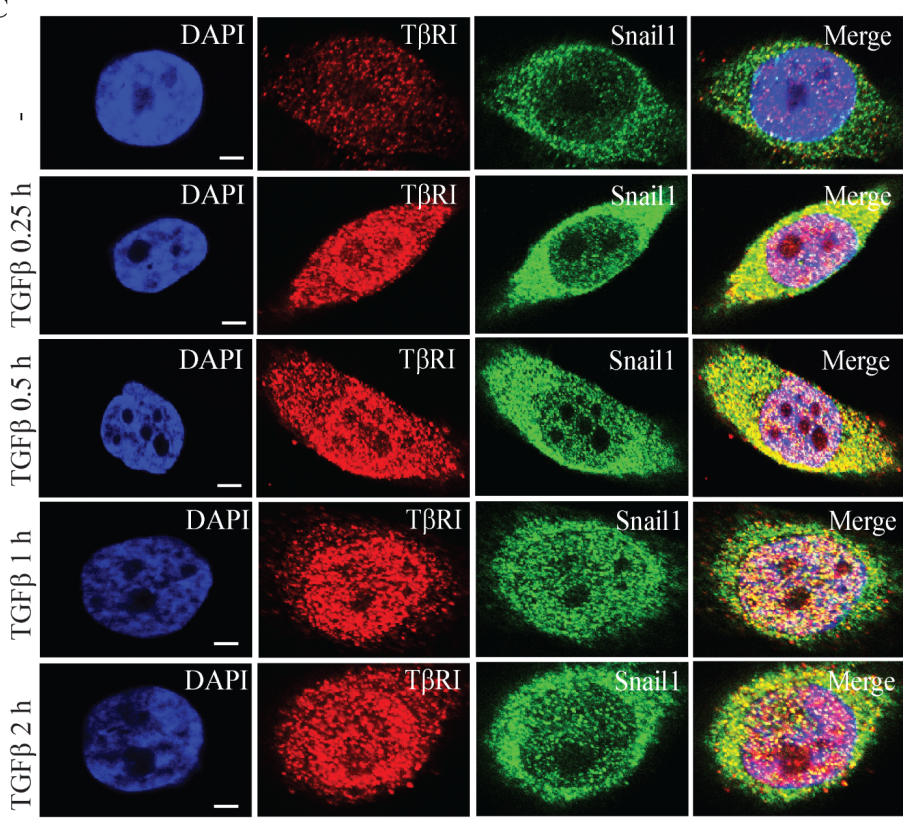

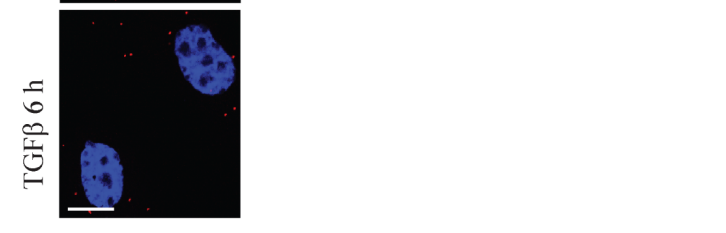

Figure 2: Snail1 interacts with T $\beta$ RI. A. PC-3U cells were treated with TGF $\beta$ for the indicated time periods. Cell lysates were prepared and immunoprecipitated with goat-Snaill and immunoblotted with rabbit T $\beta R I$ antibodies. Total cell lysates were probed for endogenous T $\beta$ RI, Snail1, and $\beta$-actin ( $n=4$ independent experiments). B. PLA images of PC-3U cells were treated with TGF $\beta$ for the indicated time periods. Cells were fixed, permeabilised and incubated with anti-rabbit T $\beta R I$ and anti-mouse Snaill antibodies, followed by incubation with PLA probes. TRRI-Snail1 PLA complexes are visualized as red dots. Quantification of T $\beta$ RI-Snaill complexes was done with the aid of Blob finder software. ( $n=4$ independent experiments). C. Representative confocal imaging of PC-3U cells treated with TGF $\beta$ for the indicated time periods. Cells were fixed, permeabilised and incubated with anti-rabbit T $\beta$ RI and anti-mouse Snaill antibodies, followed by incubation with Alexa Fluor 555 (red) secondary anti-rabbit antibodies and Alexa Fluor 488 (green) secondary anti-mouse antibodies for visualization. Merge of two layers shows co-localization of the proteins. Cell nuclei stained with DAPI $(n=3$ independent experiments). Scale bar, $20 \mu \mathrm{m}$. Bar graphs show the means $\pm \mathrm{SEM} ;{ }^{* *} P<0.005,{ }^{* * *} P<0.0005$. Differences in the means \pm SEM between samples were analyzed with two-way ANOVA and Bonferroni correction for multiple comparisons. 
A
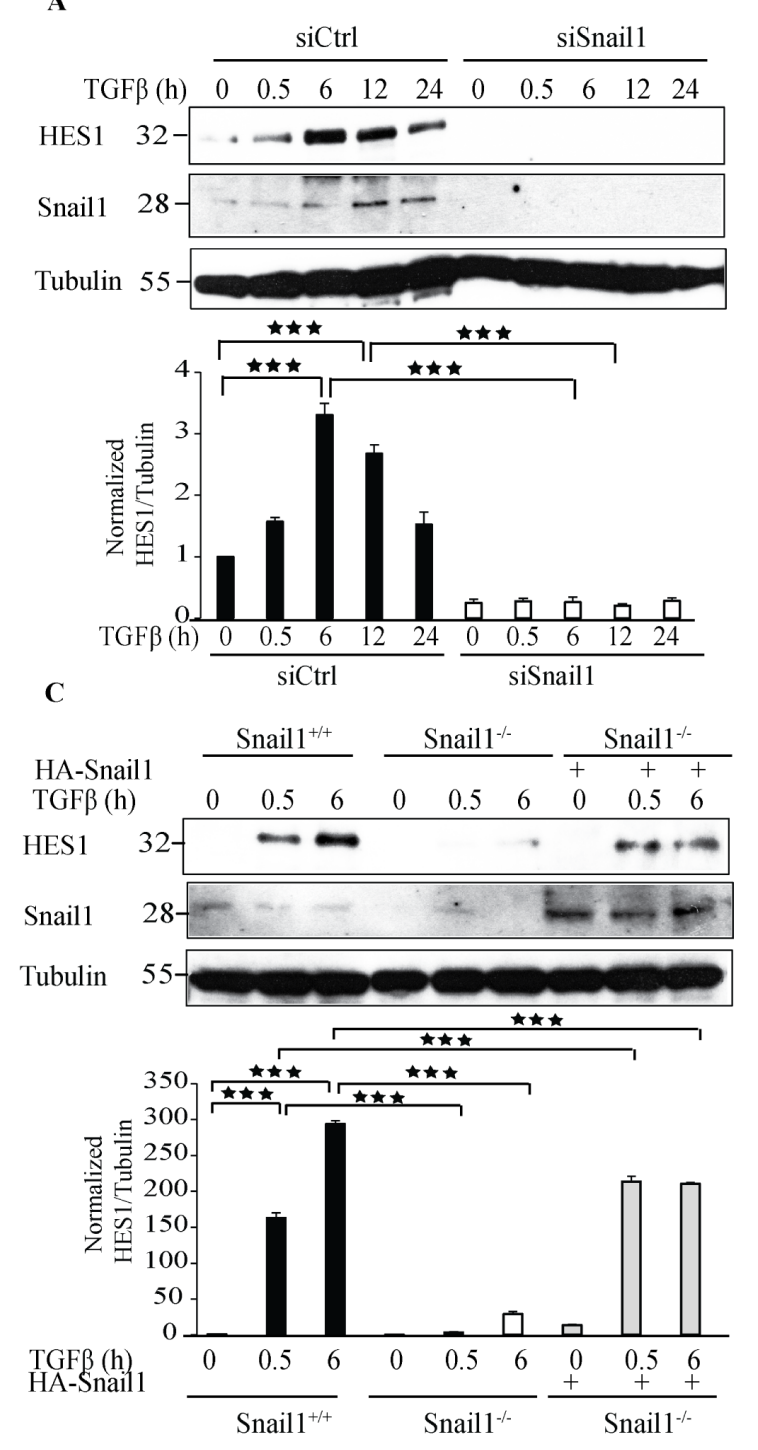

D

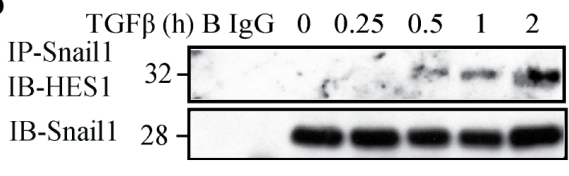

TCL

HES 1

Snaill

Actin

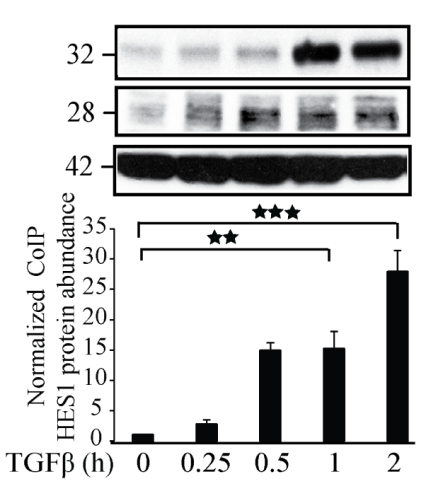

B
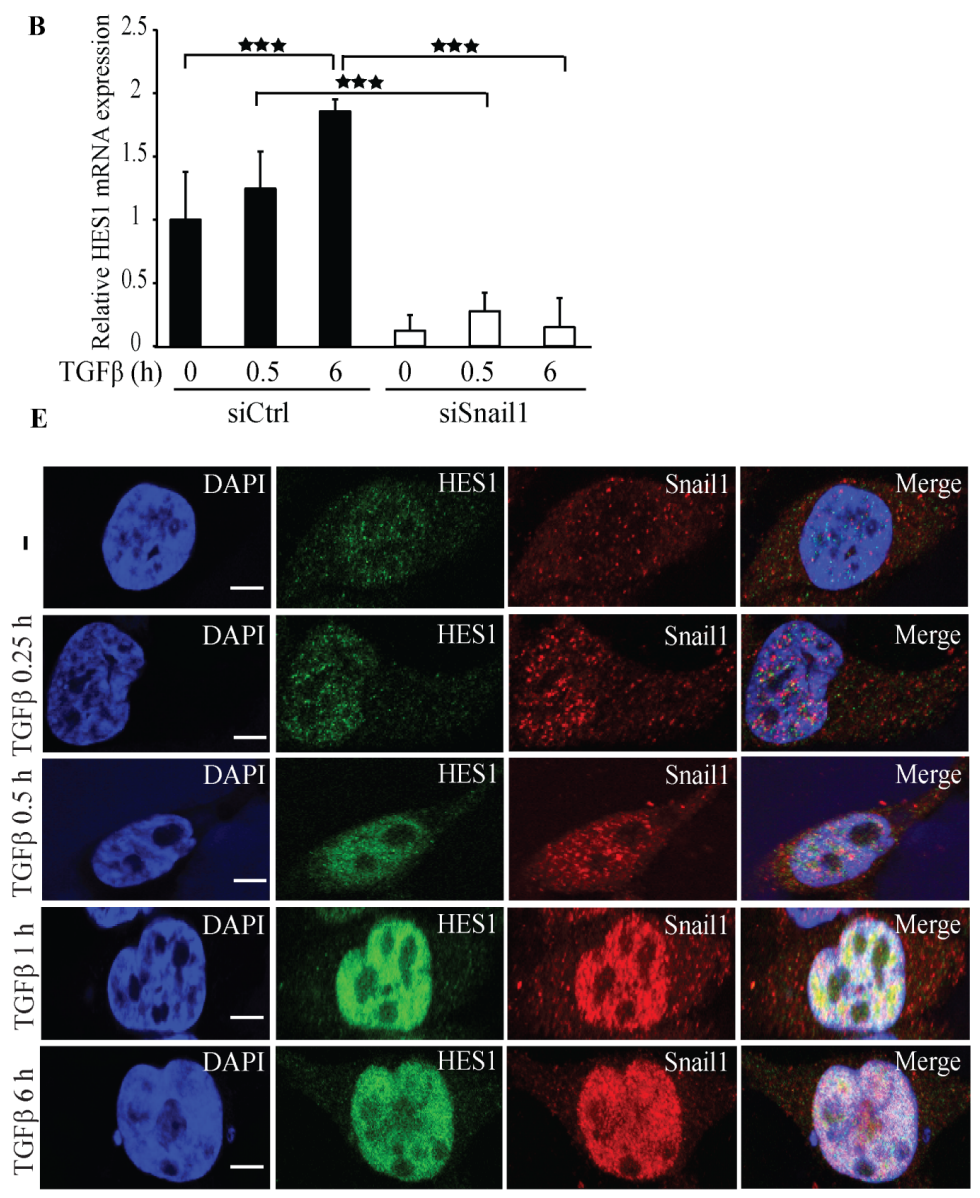

F

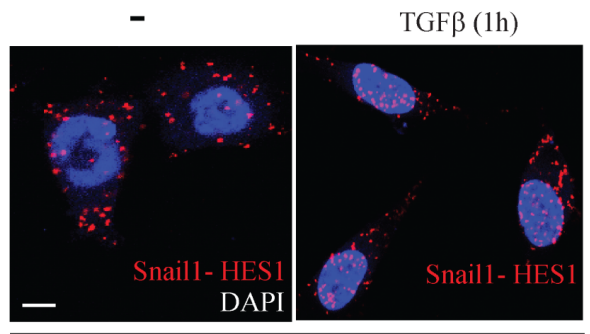

PLA assay

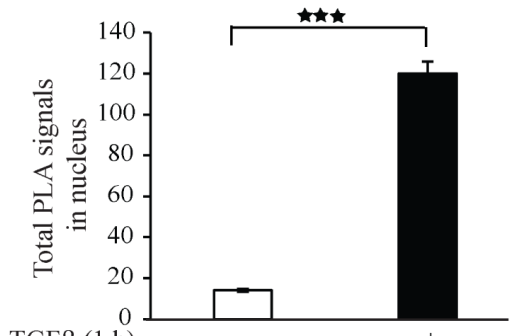

$\operatorname{TGF} \beta(1 \mathrm{~h})$

$\operatorname{TGF} \beta(1 \mathrm{~h})$

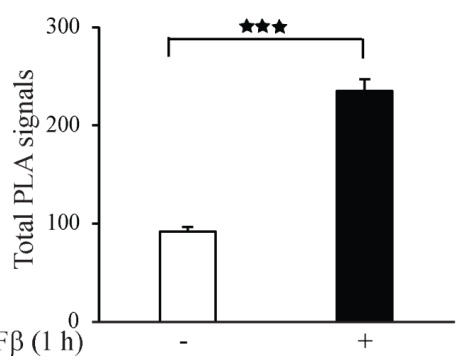


Figure 3: Knockdown of Snail1 expression by siRNA decreases Hes1 expression. A. PC-3U cells were transiently transfected with control (Ctrl) or Snaill-specific siRNA\#1 and treated with TGF $(10 \mathrm{ng} / \mathrm{ml})$ for the indicated time periods. Cell lysates were prepared and immunoblots were probed for Hes1, Snail1, and $\beta$-tubulin, which served as control for equal loading of proteins. ( $n=5$ independent experiments). B. qRT-PCR analysis of PC-3U cells transiently transfected with control (Ctrl) or Snaill-specific siRNA \#1 and treated with TGF $\beta(10 \mathrm{ng} / \mathrm{ml})$ as indicated. RNA was extracted and cDNA was prepared and used for qRT-PCR analysis of mRNA expression of Hes1. $\left(n=4\right.$ independent experiments). C. Snail1 ${ }^{+/+}$, Snail1 ${ }^{-/} \mathrm{MEFs}$, and Snail1 ${ }^{-/}$MEFs transiently transfected with HA-Snaill were serum starved and treated with TGF $\beta$ for the indicated time periods. Cell lysates were prepared and immunoblots were probed for Hes1, Snail1, and $\beta$-tubulin, which served as control for equal loading of proteins ( $n=4$ independent experiments). D. PC-3U cells were treated with TGF $\beta$ for the indicated time periods. Cell lysates were prepared and immunoprecipitated with goat-Snaill and immunoblotted with rabbit Hes 1 antibodies. Total cell lysates were probed for endogenous Hes1, Snaill, and $\beta$-actin. ( $n=4$ independent experiments). E. Representative confocal imaging of PC-3U cells treated with TGF $\beta$ for the indicated time periods. Cells were fixed, permeabilised and incubated with antirabbit Hes1 and anti-mouse Snail1 antibodies, followed by incubation with Alexa Fluor 555 (red) secondary anti- mouse antibodies and Alexa Fluor 488 (green) secondary anti-rabbit antibodies for visualization. Merge of two layers shows co-localization of the proteins. Cell nuclei stained with DAPI. ( $n=3$ independent experiments). Scale bar, $20 \mu \mathrm{m}$. F. PLA images of PC-3U cells were treated with TGF $\beta$ for the indicated time periods. Cells were harvested, fixed, permeabilised and incubated with anti-rabbit Hes1 and anti-mouse Snail1 antibodies, followed by incubation with PLA probes. Hes1-Snail1 PLA complexes are visualized as red dots. Quantification of T $\beta R I-S n a i l 1$ complexes was done with the aid of Blob finder software. $\left(n=5\right.$ independent experiments). Bar graphs show the means $\pm \mathrm{SEM} ;{ }^{* * *} P<0.005$, ${ }^{* * * *} P<$ 0.0005 . Differences in the means \pm SEM between samples were analyzed with two-way ANOVA and Bonferroni correction for multiple comparisons.

Co-immunoprecipitation experiments revealed that Hes 1 and T $\beta$ RI form a complex in a TGF $\beta$ dependent manner after $1 \mathrm{~h}$ of TGF $\beta$ stimulation of cells (Figure $5 \mathrm{~A})$. Confocal imaging supported this finding as TGF $\beta$ promoted formation of a complex between endogenous Hes 1 and T $\beta R I$ in the nucleus (Figure 5B). PLA assays also confirmed that Hes 1 and T $\beta R I$ interact, and that their interaction in the nucleus is enhanced upon TGF $\beta$ stimulation (Figure 5C). These results suggest that Hes 1 is a T $\beta \mathrm{RI}$ responsive gene and TGF $\beta$ promotes interaction and co-localization of T $\beta$ RI and Hes 1 in the nucleus.

\section{Treatment with T $\beta R I$ kinase inhibitors decreases Hes1 expression}

As we have observed that Hes 1 and T $\beta R I$ interact and form a complex in the nucleus, we investigated if the kinase activity of T $\beta R I$ is required for Hes 1 protein expression. Treatment with a commonly used and potent T $\beta$ RI inhibitor; SB-431542 decreased the expression of Hes 1 and, as expected, the phosphorylation of Smad2 (Figure 6A). Next, we ectopically overexpressed c.a. T $\beta R I$ in PC-3U cells and treated them with the T $\beta R I$ kinase inhibitor SB-431542. Consistent with our previous finding, Hes1 expression decreased upon treatment with the T $\beta R I$ kinase inhibitor, when compared with untreated cells (Figure 6B). However, Snaill expression was not affected by SB-431542 treatment (Figure 6B), in line with our previous reports that T $\beta \mathrm{RI}$ in the non-canonical signaling pathway, can promote transcription of Snail [21]. To validate our findings, we used also another T $\beta$ RI inhibitor; SB-505124 (Figure 6C), and obtained similar results regarding Hes 1 expression, as shown in Figure 6A. Taken together, these results suggest that the kinase activity of T $\beta \mathrm{RI}$ is required for Hes1 expression.

Next, we performed qRT-PCR experiments with RNA extracted from these samples. Hes 1 mRNA expression decreased significantly upon treatment with the T $\beta R I$ kinase inhibitors SB-431542 or SB-505124 (Figure 6D, 6G); in contrast, Snail1 and TRRI expression was partially decreased upon TGF $\beta$ stimulation (Figure 6E, $6 \mathrm{H})$, (Figure 6F, 6I). These results further corroborate the notion that T $\beta$ RI induces Hes 1 expression and the kinase activity of the T $\beta R I$ is required for the regulation of Hes 1 expression.

\section{Overexpression of HA-T $\beta$ RI enhances Hes1 expression}

Since we observed that silencing of T $\beta \mathrm{RI}$ decreased Hes1 expression, we next investigated if overexpression of HA-T $\beta$ RI could affect regulation of Hes1. Results from qRT-PCR analysis, showed an enhanced expression of Hes 1 upon TGF $\beta$ stimulation at increasing concentrations of HA-T $\beta$ RI (Supplementary Figure 7A), suggesting that Hes 1 is a target gene of T $\beta$ RI. However, the expression of Snail1 and Twist1 was slightly enhanced upon TGF $\beta$ stimulation at increasing concentrations of HA-T $\beta R I$, but not as much as in TGF $\beta$-stimulated cells alone (Supplementary Figure 7B-7C). As expected, TGF $\beta$ stimulation enhanced the expression of T $\beta$ RI mRNA (Supplementary Figure 7D). These results further strengthen the notion that T $\beta$ RI regulates Hes 1 expression.

\section{T $\beta R I$ induces EMT genes}

Since we observe that Snaill regulates T $\beta R I$ expression and since Snail1 is a bonafide master regulator of EMT genes, we investigated if the Snaill regulated EMT genes are affected upon downregulation of T $\beta$ RI. Treatment with TGF $\beta$ in the control cells upregulated mesenchymal genes, such as Fibronectin1, N-cadherin, the Notch responsive gene Jagged1, and Zeb1, compared 
to siT $\beta R I$ treated cells (Supplementary Figure 8A-8D). As expected, the T $\beta R I$ mRNA expression was downregulated in the siT $\beta$ RI treated cells (Supplementary 8E) and also the classical TGF $\beta$ target genes; Smad7 and PAI-1 (Supplementary Figure 8F-8G). The mRNA expression of Snail1 also decreased in the siT $\beta$ RI treated group (Supplementary Figure 8H). These results suggest that the Snaill regulation of T $\beta$ RI, in turn, promotes transcription of classical EMT genes.
A



B

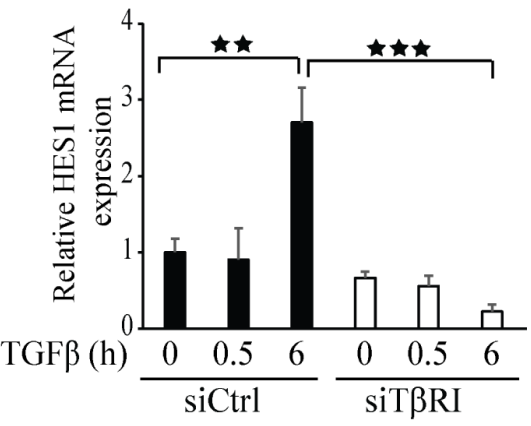

C

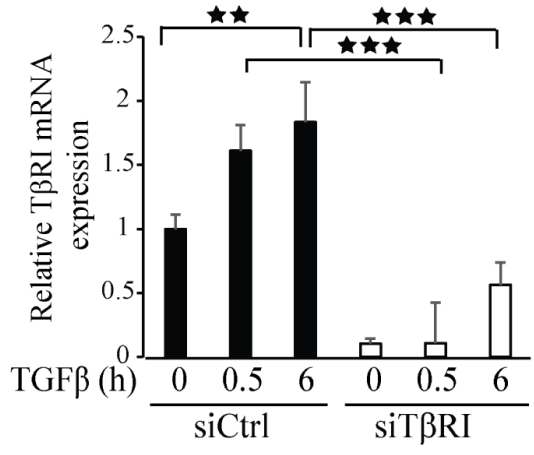

D

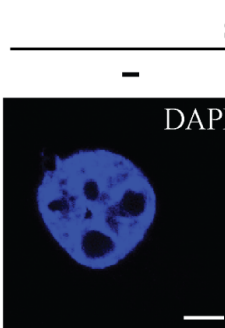

siCtrl

TGF $\beta 1 \mathrm{~h}$
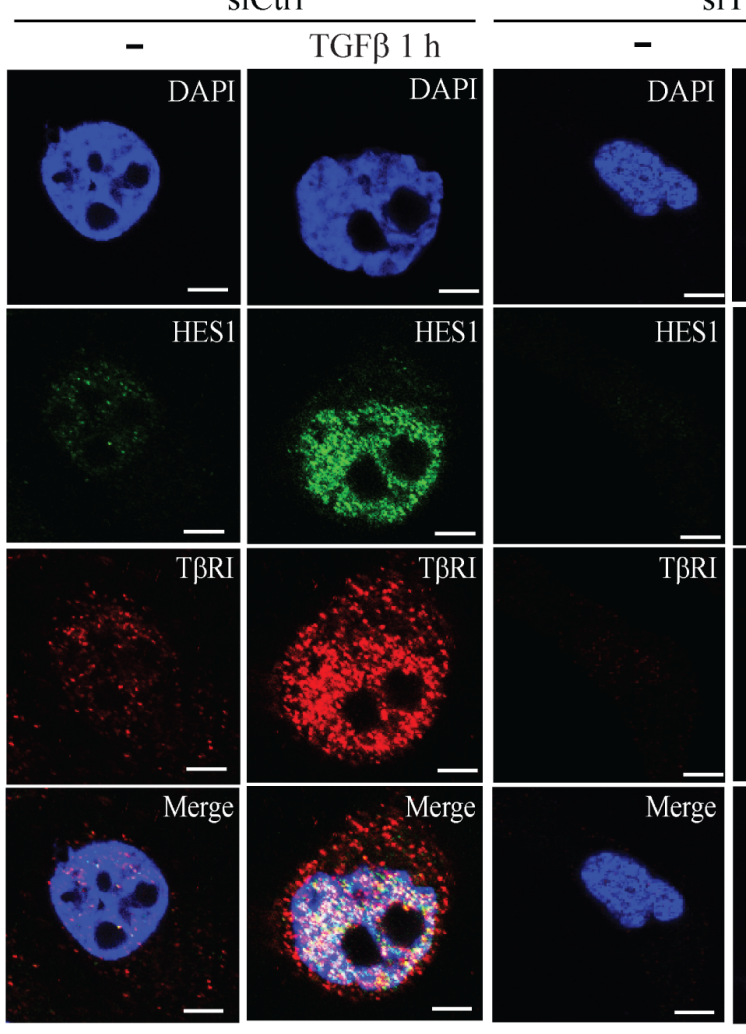

$\operatorname{siT} \beta R I$
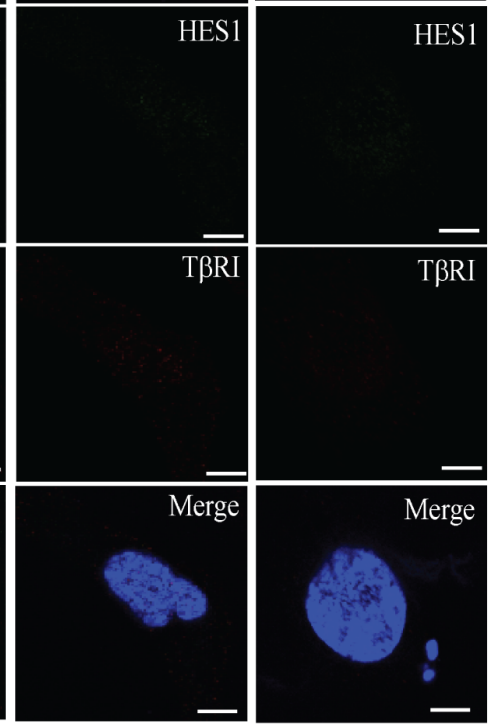

Figure 4: Knockdown of TßRI expression by siRNA decreases Hes1 expression. A. PC-3U cells were transiently transfected with control (Ctrl) or T $\beta$ RI-specific siRNA and treated with TGF $\beta(10 \mathrm{ng} / \mathrm{ml})$ for the indicated time periods. Cell lysates were prepared and immunoblots were probed for Hes1, T $\beta R I$, and $\beta$-tubulin, which served as control for equal loading of proteins. ( $n=5$ independent experiments). B.-C. qRT-PCR analysis of PC-3U cells transiently transfected with control (Ctrl) or T $\beta$ RI-specific siRNA and treated with TGF $\beta(10 \mathrm{ng} / \mathrm{ml})$ as indicated. RNA was extracted and cDNA was prepared and used for qRT-PCR analysis of mRNA expression of Hes 1 and T $\beta$ RI. ( $n=4$ independent experiments). D. Confocal images of PC-3U cells transfected with control (Ctrl) or T $\beta R I-s p e c i f i c ~ s i R N A$. $48 \mathrm{~h}$ post transfection, cells were incubated in low serum containing medium for $24 \mathrm{~h}$ followed by treatment with TGF $\beta$ (10 $\mathrm{ng} / \mathrm{ml})$ for the indicated time periods. Cells were fixed, permeabilised and incubated with anti-rabbit T $\beta R I$ and anti-mouse Hes 1 antibodies, followed by incubation with Alexa Fluor 555 (red) secondary anti-rabbit antibodies and Alexa Fluor 488 (green) secondary anti-mouse antibodies for visualization. Merge of two layers shows co-localization of the proteins. Cell nuclei stained with DAPI. ( $n=3$ independent experiments). Scale bar, $20 \mu \mathrm{m}$; Bar graphs show the means $\pm \mathrm{SEM} ;{ }^{* *} P<0.005,{ }^{* * *} P<0.0005$. Differences in the means \pm SEM between samples were analyzed with two-way ANOVA and Bonferroni correction for multiple comparisons. 


\section{TGF $\beta$ stimulates sumoylation of Snail1}

The activity and stability of proteins is regulated by post-translational modifications $[39,40]$. To explore if
Snail1 is sumoylated, we subjected lysates from untreated or TGF $\beta$-treated PC-3U cells to immunoprecipitation with a Snail1 antiserum followed by immunoblotting with an antiserum against Sumo1. TGF $\beta$ treatment
A
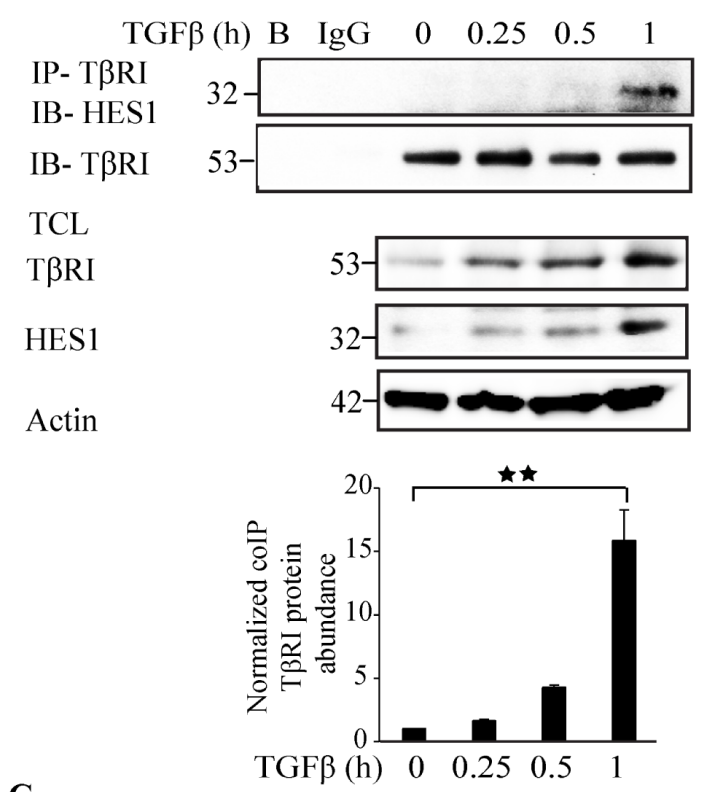

C
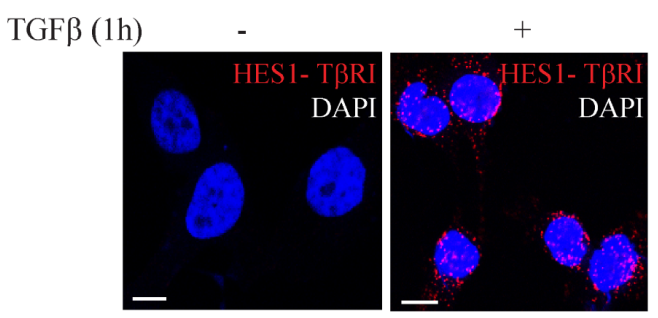

B
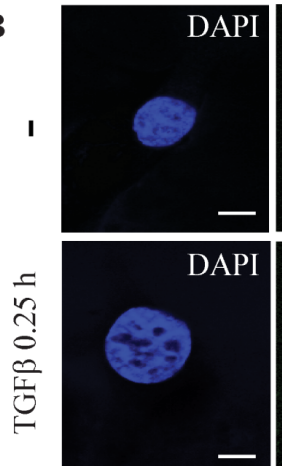

$\frac{1}{n}$
0
0
0
0
0
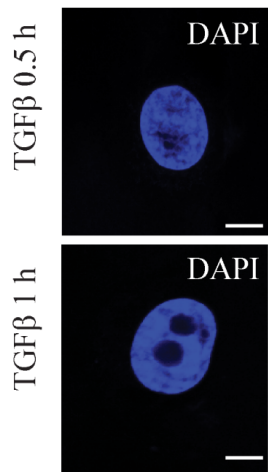

DAPI

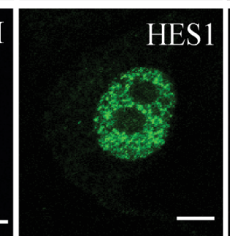

$\frac{5}{0}$
$\frac{0}{0}$
0
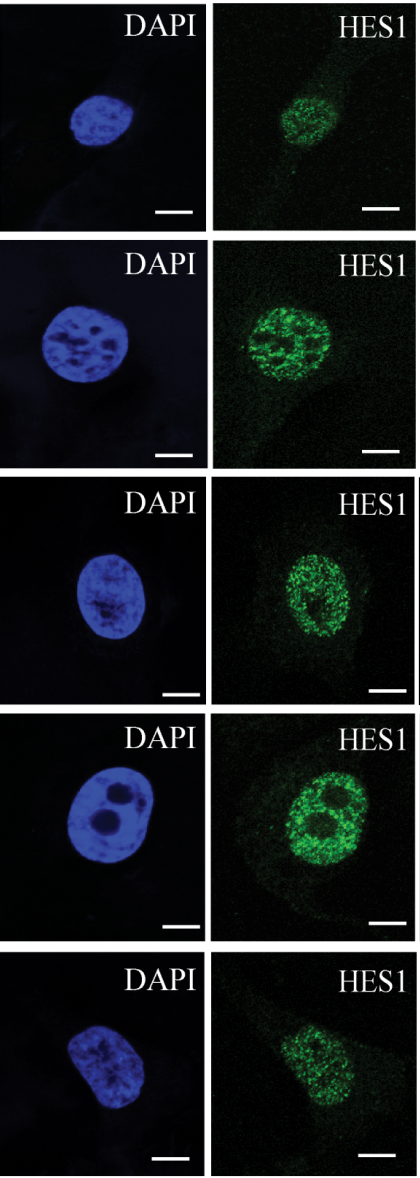
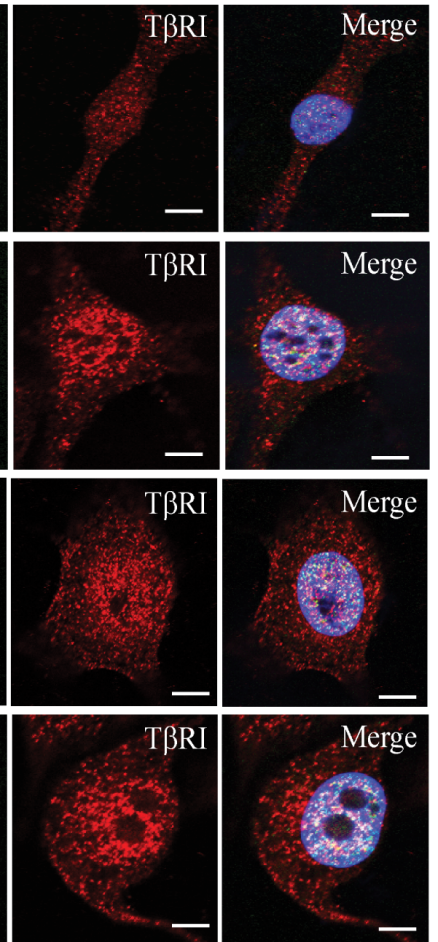
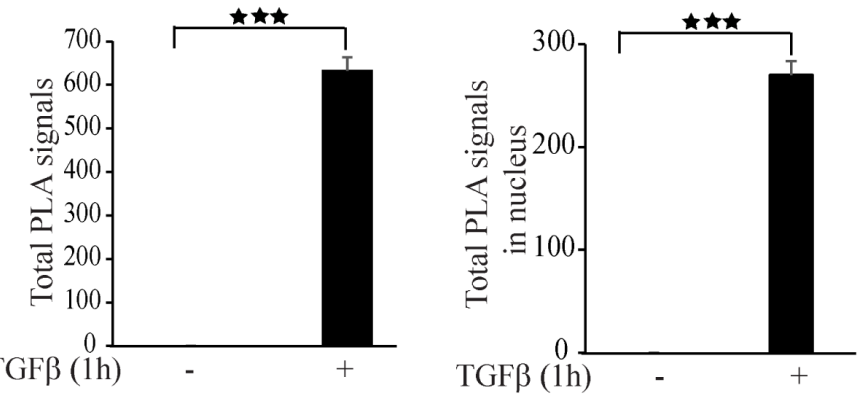

Figure 5: Hes1 interacts with TßRI. A. PC-3U cells were treated with TGF $\beta$ for the indicated time periods. Cell lysates were prepared and immunoprecipitated with rabbit-T $\beta$ RI and immunoblotted with rabbit-Hes 1 antibodies. Total cell lysates were probed for endogenous T $\beta R I$, Hes1, and $\beta$-actin. ( $n=4$ independent experiments). B. Representative confocal imaging of PC-3U cells treated with TGF $\beta$ for the indicated time periods. Cells were fixed, permeabilised and incubated with anti-rabbit T $\beta R I$ and anti-mouse Hes 1 antibodies, followed by incubation with Alexa Fluor 555 (red) secondary anti-rabbit antibodies and Alexa Fluor 488 (green) secondary anti-mouse antibodies for visualization. Merge of two layers shows co-localization of the proteins. Cell nuclei stained with DAPI. ( $n=3$ independent experiments). Scale bar, $20 \mu \mathrm{m}$. C. PLA images of PC-3U cells were treated with TGF $\beta$ for the indicated time periods. Cells were fixed, permeabilised and incubated with anti-rabbit T $\beta R I$ and anti-mouse Hes 1 antibodies, followed by incubation with PLA probes. T $\beta$ RI-Hes1 PLA complexes are visualized as red dots. Quantification of T $\beta$ RI-Snaill complexes was done with the aid of Blob finder software. ( $n=3$ independent experiments). Scale bar, $20 \mu \mathrm{m}$. Bar graphs show the means $\pm \mathrm{SEM} ;{ }^{* *} P<0.005,{ }^{* * *} P<0.0005$. Differences in the means \pm SEM between samples were analyzed with two-way ANOVA and Bonferroni correction for multiple comparisons. 
A

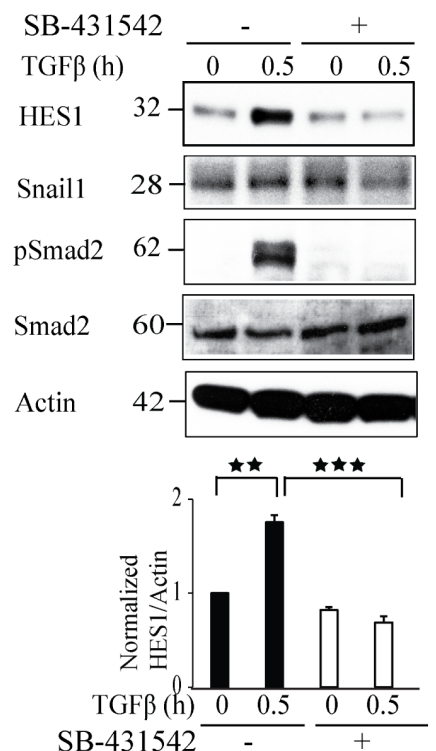

SB-431542 - $\frac{1}{+}$

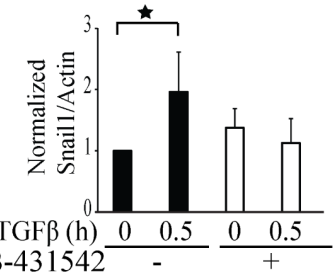

D

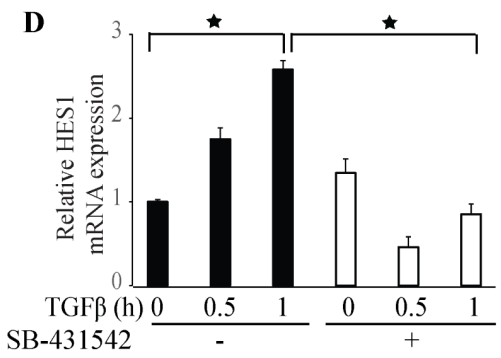

\section{G}

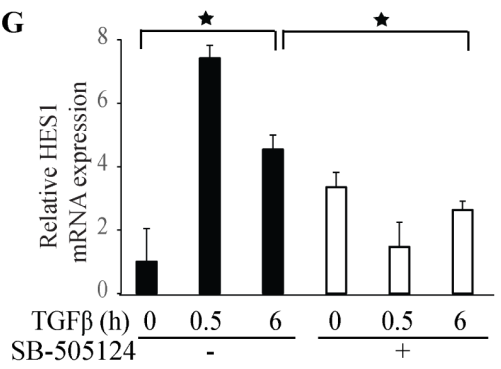

B

SB-431542

TGF $\beta$ (h)
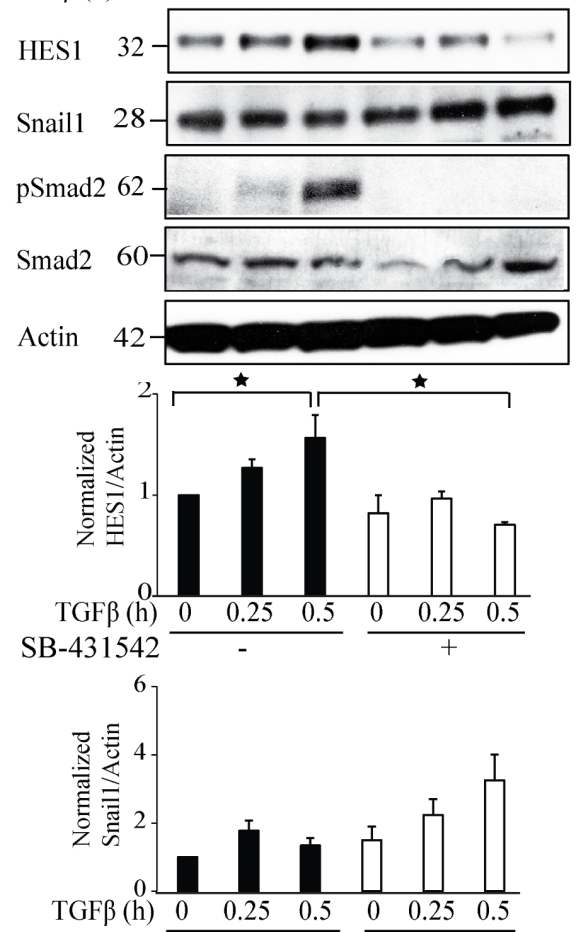

SB-431542

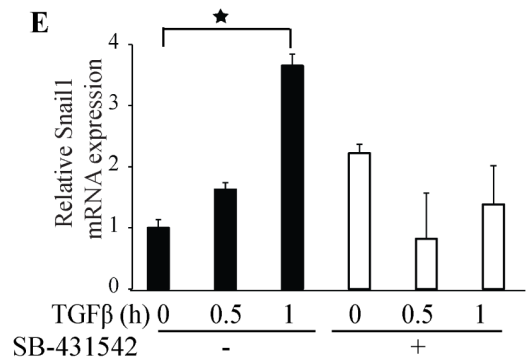

H

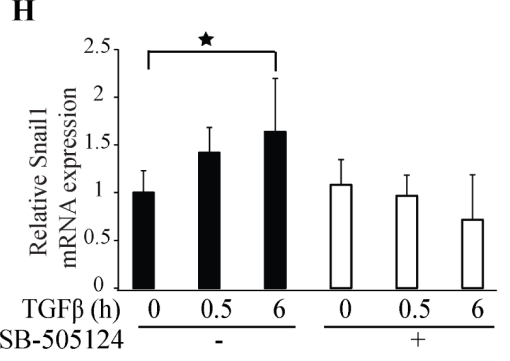

C SB-505124

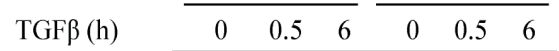
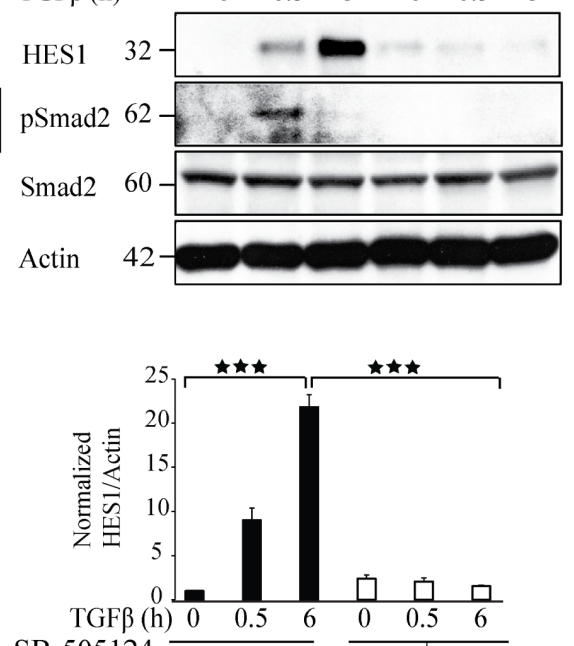

SB-505124
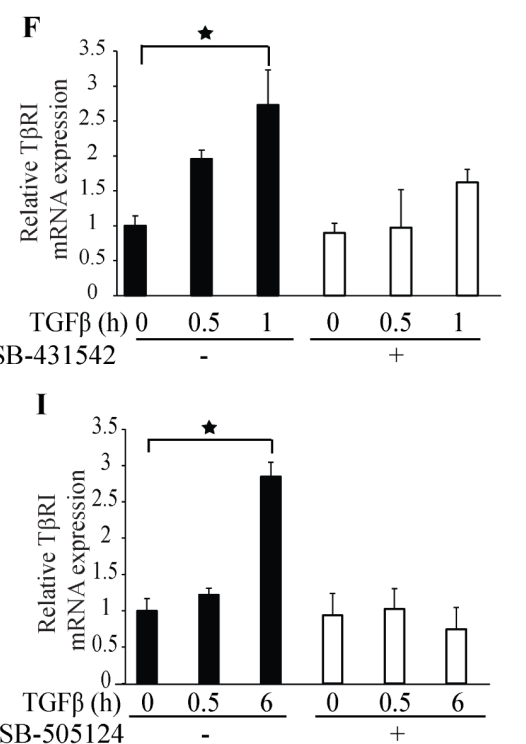

Figure 6: Treatment with T $\beta$ RI kinase inhibitors decreases Hes1 expression. A. PC-3U cells were treated with TGF $\beta$ for the indicated time periods. The cells were pretreated for $1 \mathrm{~h}$ with T $\beta$ RI kinase inhibitor (SB431542) before TGF $\beta$ treatment. Cell lysates were prepared and immunoblotted with Hes1, Snail1, p-Smad2, Smad2 and $\beta$-actin antibodies. ( $n=4$ independent experiments). B. PC-3U cells were transiently transfected with HA-T $\beta$ RI and treated with TGF $\beta$ for the indicated time periods. The cells were pretreated for $1 \mathrm{~h}$ with T $\beta R I$ kinase inhibitor (SB431542) before TGF $\beta$ treatment. Cell lysates were prepared and immunoblotted with Hes1, Snail1, p-Smad2, Smad2 and $\beta$-actin antibodies. ( $n=4$ independent experiments). C. PC-3U cells were treated with TGF $\beta$ for the indicated time periods. The cells were pretreated for $1 \mathrm{~h}$ with T $\beta$ RI kinase inhibitor (SB505124) before TGF $\beta$ treatment. Cell lysates were prepared and immunoblotted with Hes1, Snail1, p-Smad2, Smad2 and $\beta$-actin antibodies. ( $n=4$ independent experiments). D.-I. qRT-PCR analysis of PC-3U cells pretreated with T $\beta$ RI kinase inhibitors (SB431542 or SB505124) for 1h and stimulated with TGF $\beta$ as indicated. RNA was extracted and cDNA was prepared and used for qRT-PCR analysis of mRNA expression of Hes1, Snail1, T $\beta R I$. ( $n=4$ independent experiments). Bar graphs show the means \pm SEM; ${ }^{*} P<0.05,{ }^{* *} P<0.005,{ }^{* * *} P<0.0005$. Differences in the means \pm SEM between samples were analyzed with two-way ANOVA and Bonferroni correction for multiple comparisons. 
A

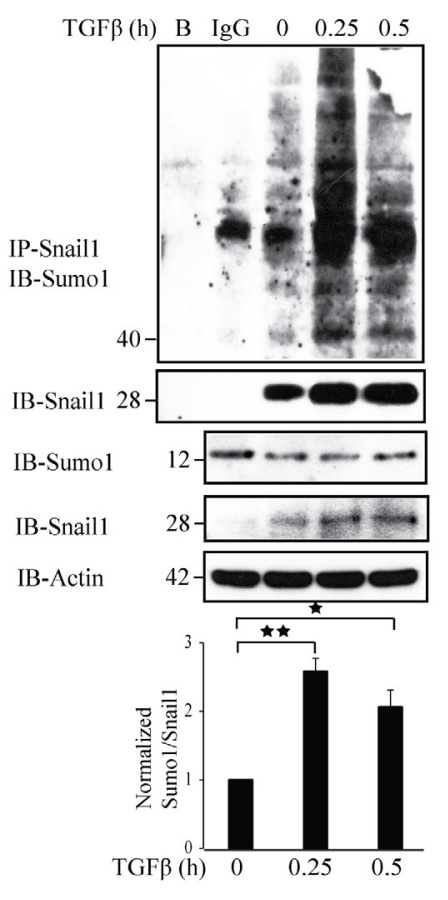

D

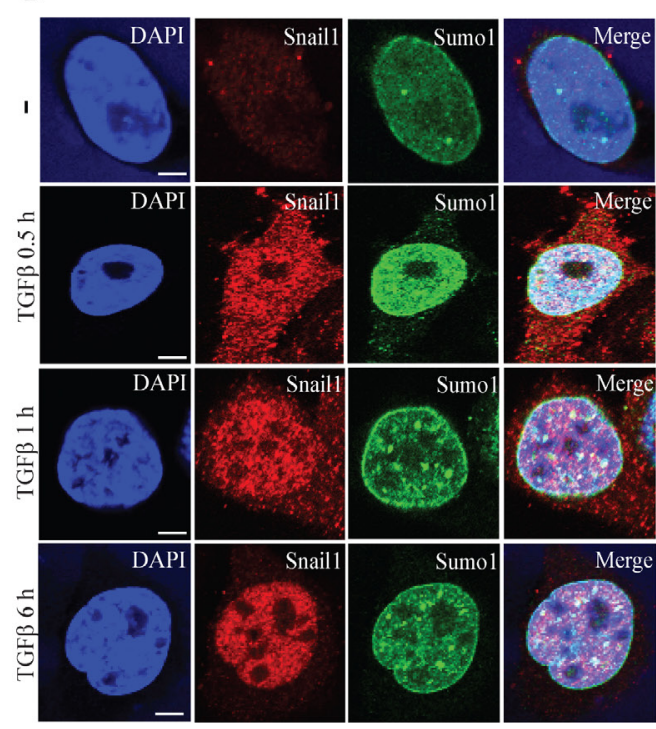

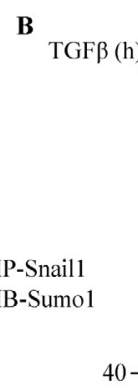

IB-Snail1 28

IB-HA

IB-Snail1

IB-Actin

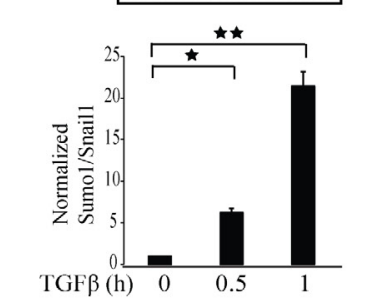

$\mathbf{E}$
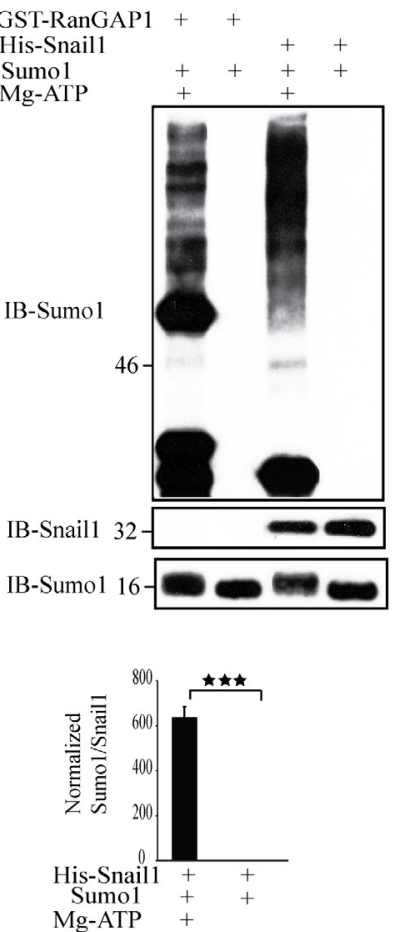
TGF $\beta(h)$

0.5


PLA assay
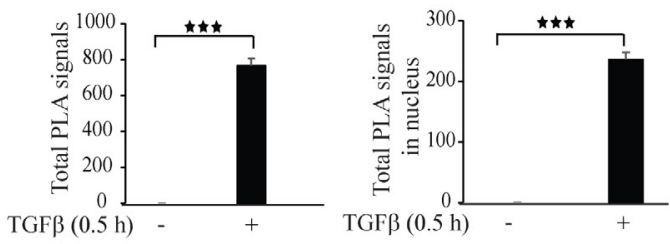

Figure 7: TGFß stimulates sumoylation of Snail1. A. PC-3U cells were treated with TGF $\beta$ for the indicated time periods. Cell lysates were subjected to sumoylation assay and immunoprecipitated with goat-Snail1 and immunoblotted with rabbit-Sumo1 antibodies. Total cell lysates were probed for endogenous Sumo1, Snail1, and $\beta$-actin. ( $n=5$ independent experiments). B. PC-3U cells were transiently transfected with HA-Sumol and treated with TGF $\beta$ for the indicated time periods. Cell lysates were subjected to sumoylation assay and immunoprecipitated with goat-Snaill and immunoblotted with rabbit-Sumol antibodies. Total cell lysates were probed for HA and endogenous Snail1, and $\beta$-actin. ( $n=5$ independent experiments). C. His-Snail1 and GST-RanGAP1 (positive control) incubated with Sumo1 was subjected to in vitro sumoylation reaction for $60 \mathrm{~min}$ in the presence or absence of Mg-ATP. Reaction was terminated by adding sample buffer and boiling at $95^{\circ} \mathrm{C}$. Samples were immunoblotted with anti-Sumol and anti-Snaill antibodies. ( $n=6$ independent experiments). D. Representative confocal imaging of PC-3U cells treated with TGF $\beta$ for the indicated time periods. Cells were fixed, permeabilised and incubated with anti-mouse Snail1 and anti-rabbit Sumo1 antibodies, followed by incubation with Alexa Fluor 555 (red) secondary anti-mouse antibodies and Alexa Fluor 488 (green) secondary anti-rabbit antibodies for visualization. Merge of two layers shows co-localization of the proteins. Cell nuclei stained with DAPI. ( $n=3$ independent experiments). Scale bar, $20 \mu$ m; E. PLA images of PC$3 \mathrm{U}$ cells were treated with TGF $\beta$ for the indicated time periods. Cells were harvested, fixed, permeabilised and incubated with anti-rabbit Sumo1 and anti-mouse Snail1 antibodies, followed by incubation with PLA probes. Sumo1-Snail1 PLA complexes are visualized as red dots. Quantification of Sumo1-Snail1 PLA complexes was done with the aid of Blob finder software. ( $n=3$ independent experiments). Scale bar, $20 \mu \mathrm{m}$. Bar graphs show the means $\pm \mathrm{SEM} ;{ }^{*} P<0.05,{ }^{*} P<0.005,{ }^{* * *} P<0.0005$. Differences in the means \pm SEM between samples were analyzed with two-way ANOVA and Bonferroni correction for multiple comparisons. 
Human SNAIL1 SRAFADRSNLRAHLQTHSDVKKYQCQACARTFSRMSLLHKHQESGCSGCPR

Sumoylation consensus motif $\psi \mathrm{KXE}$

C



B

HA-Wt-Snail1 HA-Mut-Snail1

TGF $\beta$ (h) $\operatorname{IgG} \overline{00.250 .5} \overline{00.250 .5}$

$$
\begin{aligned}
& \text { Sumoylation consensus motif VKKY } \\
& \text { in human Snail1 } \\
& \psi \text { - hydrophobic amino acid }
\end{aligned}
$$

$\mathrm{X}$ - any amino acid
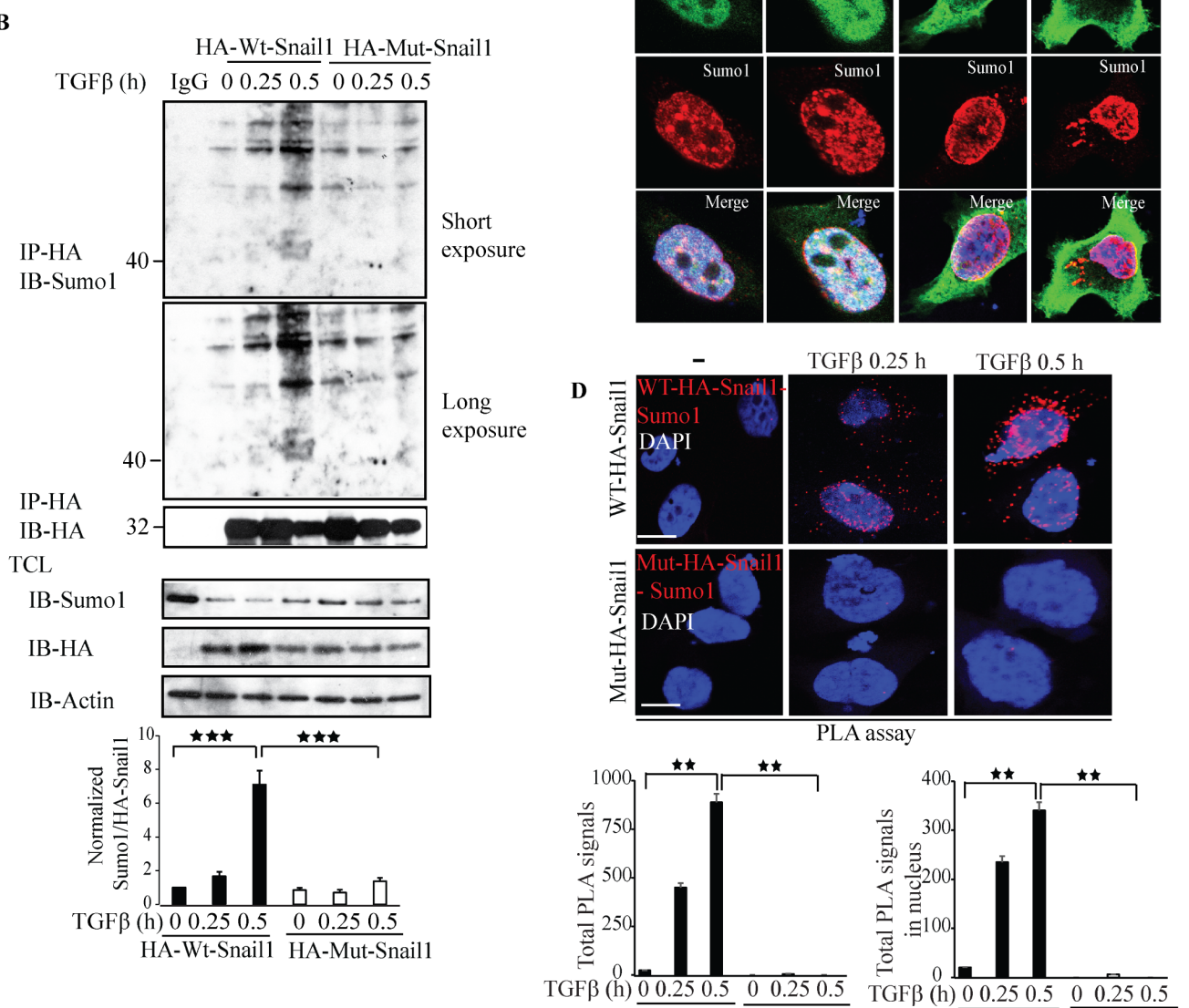

HA-WT-Snail1 $\overline{\text { HA-Mut-Snaill HA-WT-Snail1 }} \overline{\text { HA-Mut-Snail }}$

Figure 8: Lysine 234 is required for Sumo1 modification of Snail1. A. In silico analysis using Clustal W alignment of protein sequences of Snail1 and Snail2 (slug) of human and mice showing conserved lysine (K) residues. B. PC-3U cells were transiently transfected with HA-WT-Snaill or Mutant-HA-Snaill and treated with TGF $\beta$ for the indicated time periods. Cell lysates were subjected to sumoylation assay and immunoprecipitated with mouse-HA antibodies and immunoblotted with rabbit-Sumo1, mouse-HA antibodies. Total cell lysates were probed for endogenous Sumo1, HA, and $\beta$-actin. ( $n=5$ independent experiments). C. Representative confocal imaging of PC-3U cells transiently transfected with HA-WT-Snaill or Mutant-HA-Snaill and treated with TGF $\beta$ for the indicated time periods. Cells were harvested, fixed, permeabilised and incubated with anti-mouse HA-Snail1 and anti-rabbit Sumo1 antibodies, followed by incubation with Alexa Fluor 555 (red) secondary anti-rabbit antibodies and Alexa Fluor 488 (green) secondary anti-mouse antibodies for visualization. Merge of two layers shows co-localization of the proteins. Cell nuclei stained with DAPI. ( $n=3$ independent experiments). Scale bar, $20 \mu \mathrm{m}$. D. PLA images of PC-3U cells transiently transfected with HA-WT-Snaill or Mutant-HA-Snaill and treated with TGF $\beta$ for the indicated time periods. Cells were harvested, fixed, permeabilised and incubated with anti-rabbit Sumol and anti-mouse HA antibodies, followed by incubation with PLA probes. Sumo1-HA-Snail1 PLA complexes are visualized as red dots. Quantification of Sumo1- HASnail1 PLA complexes was done with the aid of Blob finder software. ( $n=3$ independent experiments). Scale bar, $20 \mu \mathrm{m}$. Bar graphs show the means \pm SEM; ${ }^{*} P<0.05,{ }^{* *} P<0.005,{ }^{* * *} P<0.0005$. Differences in the means \pm SEM between samples were analyzed with two-way ANOVA and Bonferroni correction for multiple comparisons. 
for $0.25 \mathrm{~h}$ induced a band at $40 \mathrm{kDa}$ corresponding to polysumolyated Snail1 (Figure 7A). Next, we ectopically expressed HA-Sumo1 in PC-3U cells and treated with TGF $\beta$, or not, and performed sumoylation assays. We observed a band at $40 \mathrm{kDa}$, which had the expected size of sumoylated Snail1 (Figure 7B). To further validate our findings, we performed in vitro sumoylation assays. Incubation of His-Snail1 with Sumo1 generated a band at $46 \mathrm{kDa}$, suggesting that His-Snaill is sumoylated in vitro (Figure 7C). As a positive control RanGAP1 was used and found to be sumoylated in presence, but not in the absence of magnesium-ATP (Mg-ATP), which is essential for the conjugation of the substrate to the E1 activation enzyme and hence are derived from the SUMO cascade. These results showed that Snail1 was sumoylated by Sumo1 in vitro (Figure 7C). However, in vitro sumoylation assays with Sumo2 did not induce a product (Supplementary Figure 9). In addition, to investigate if sumoylation of Snaill can be observed also in other cancer cells, we ectopically expressed HA-Sumo1 in breast cancer cells MDA-MB-231, and lung cancer cells A549. The cells were then treated with TGF $\beta$, or not, and sumoylation assays were performed. TGF $\beta$ treatment of these cancer cells resulted also in sumoylation of Snail1, Supplementary
A

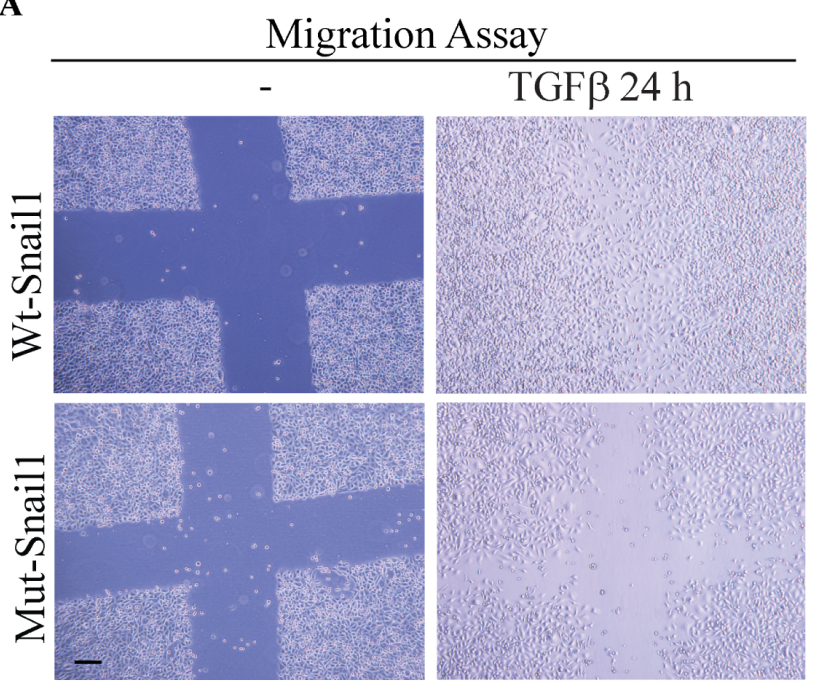

B

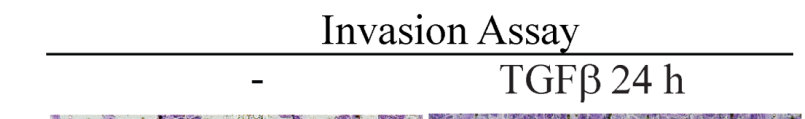

\section{(1)}

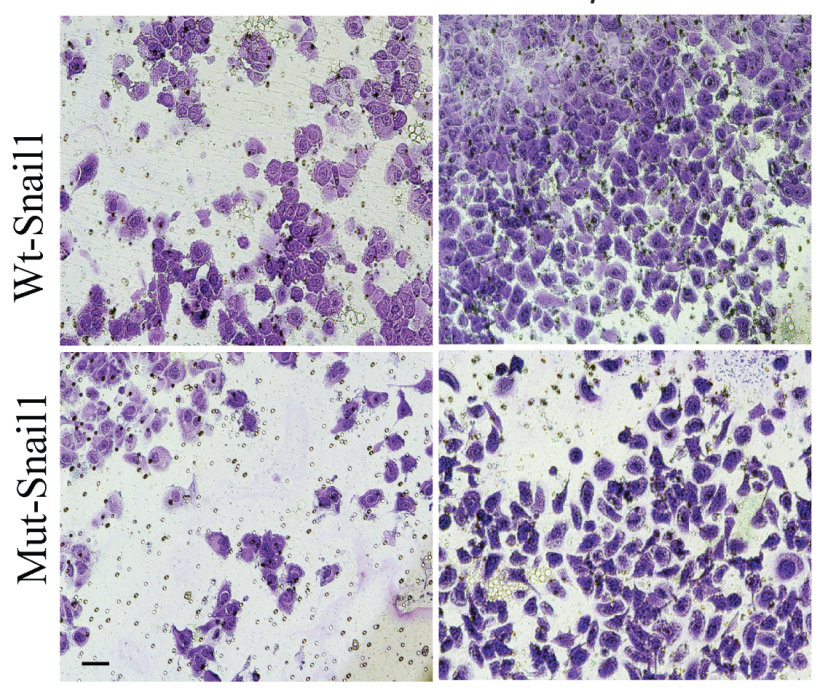

$c$

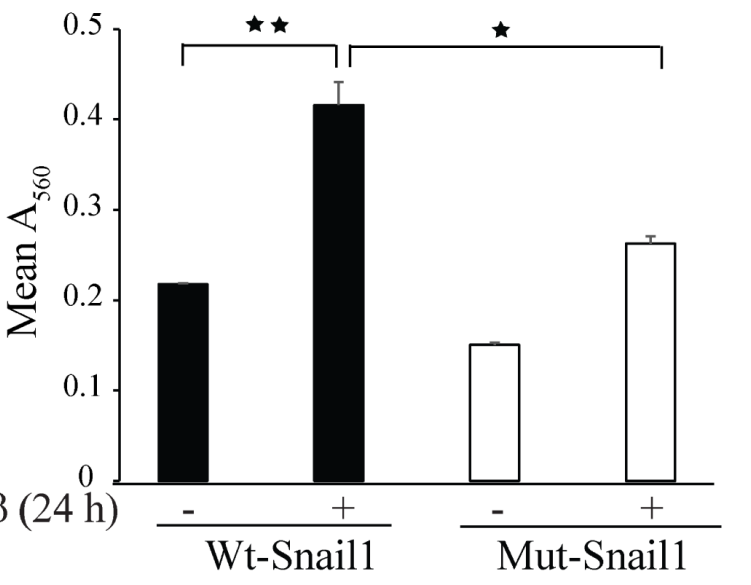

Figure 9: Sumoylation deficient Mut-Snail1 is deprived of migration and invasive properties. A. In vitro wound healing assay was performed with PC-3U cells which were transiently transfected with HA-WT-Snaill or Mutant-HA-Snaill. Thereafter, cells were starved in $1 \%$ FBS containing medium for $24 \mathrm{~h}$ and treated with TGF $\beta$ for the indicated time periods. Phase-contrast images were taken before and after treatment with TGF $\beta$. Bar indicates $200 \mu \mathrm{m}$. B. Representative images of invasive PC-3U cells transiently transfected with HA-WT-Snaill or Mutant-HA-Snail1, treated with TGF $\beta$ as indicated. Invasive cells were visualized by staining with crystal violet cell stain solution. C. Graph represents mean values for optical density (OD) of invasive PC-3U cells transfected with HA-Snaill or MutantHA-Snaill, and treated with or without TGF $\beta$ for the indicated time periods ( $n=5$ independent experiments). Bar graphs show the means $\pm \mathrm{SEM} ;{ }^{*} P<0.05,{ }^{* *} P<0.005$. Differences in the means \pm SEM between samples were analyzed with two-way ANOVA and Bonferroni correction for multiple comparisons. 
Figure 10A, 10B. By using confocal imaging, we observed that TGF $\beta$ promotes a co-localization between Sumo1 and Snail1 in PC-3U cells (Figure 7D). Moreover, a PLA assay also showed that Snaill and Sumol interact in a TGF $\beta$-dependent manner in PC-3U, MDA-MB-231, and A549 cells (Figure 7E, Supplementary Figure 10C, 10D). Taken together, these results suggest that TGF $\beta$ stimulates sumoylation of Snail1, in aggressive prostate, breast and lung cancer cells.

\section{Lysine 234 is required for Sumo1 modification of Snail1}

As we have observed that Snail1 is sumoylated upon TGF $\beta$ treatment, we investigated the possible acceptor lysine residue in Snail1 that is subjected to sumoylation. Using in silico analysis, we identified K234 as a possible acceptor lysine residue for Sumoylation of Snail1, (Figure 8A). Therefore, we generated a K234R mutant Snail1 by mutating K234 to arginine. We transiently transfected either wild type Snail1 (wt Snail1) or K234R mutant Snaill in PC-3U cells and performed cell based sumoylation assays. Treatment with TGF $\beta$ induced a band corresponding to $40 \mathrm{kDa}$ only in wt-Snaill transfected group but not in cells transfected with K234R mutant Snaill (Figure 8B), suggesting that K234R is a major acceptor lysine in Snail1 for sumoylation. By confocal imaging, we showed that Snaill and Sumol co-localize and form a complex only in wt-Snaill transfected cells but not in cells transfected with the K234R mutant Snail1 (Figure 8C), further confirming that the K234R is a crucial sumoylation site in Snail1. By PLA assays we observed that wt Snail1, but not the K234R mutant, interacted with Sumo1 in a TGF $\beta$-dependent manner (Figure 8D). Moreover, qRT-PCR analysis revealed that wt-Snail1 promoted transcription of other EMT inducers, such as Slug, Zeb1, and T $\beta R I, c-J u n$, and TGF $\beta$ responsive genes such as Smad7 and PAI-1, in transiently transfected PC3U cells, but not K234R mutant (Supplementary Figure $11 \mathrm{~A}-11 \mathrm{~F})$. These results suggest that lysine 234 is an acceptor residue for sumoylation of Snail1, as mutation of lysine 234 to arginine (K234R) abolished Snail1 sumoylation, and its capability to promote transcription of EMT genes.

\section{Sumoylation-deficient K234R mutant Snail1 does not promote migration and invasion}

To investigate the functional properties of the sumoylation-deficient K234R mutant Snail1, we performed cell migration assays in PC-3U cells transfected with either wt-Snaill or K234R mutant Snail1. Using scratch assays, in the presence or absence of TGF $\beta$ treatment, we found that wt Snail1, but not K234R mutant Snail1, promoted migration of PC-3U cells (Figure 9A).
As Snaill is regarded as the master regulator of the EMT program and as invasiveness is considered to be a hallmark of cells undergoing EMT, we next performed invasive assays in PC-3U cells transfected with either wt or K234R mutant Snail1. TGF $\beta$ treatment for $24 \mathrm{~h}$ conferred invasiveness only in cells transfected with wt Snail1, but not in cells transfected with K234R mutant Snail1 (Figure 9B, 9C). These results further supports the notion that sumoylation deficient-Snail1 is unable to promote migration and invasion in prostate cancer cells.

\section{TGF $\beta$ promotes Snail1 and c-Jun interaction and co-localization}

We have previously reported that c-Jun binds to the Snaill promoter and regulates Snaill expression. We investigated if Snaill and c-Jun interact, by performing an endogenous co-immunoprecipitation assay; treatment with TGF $\beta$ enhanced interaction between Snaill and c-Jun (Figure 10A). Confocal imaging and PLA assays also supported the notion that Snaill and c-Jun co-localize and interact in the nucleus in a TGF $\beta$-dependent manner (Figure 10B). Interestingly, only wt-Snail1 interacted with c-Jun, while the sumoylation-deficient K234R mutant Snaill did not, suggesting that sumoylation of Snaill is required for interaction between Snaill and c-Jun (Supplementary Figure 12). PLA assays also supported our finding that Snaill and c-Jun interact in a TGF $\beta$-dependent manner (Figure 10C).

Next, we confirmed our previous finding that c-Jun binds to Snaill promoter by ChIP assays and explored the possibility that c-Jun binds to the TRRI promoter [30]. Treatment of PC-3U cells with TGF $\beta$ enhanced c-Jun binding to T $\beta R I$ and Snaill promoters (Figure 10D-10F), suggesting that c-Jun binds to both Snail1 and T $\beta R I$ promoters to regulate their expression. Moreover, knockdown of endogenous Snaill protein expression inhibited the binding of c-Jun to the Snaill and TRRI promoters (Figure 10G-10I), suggesting that Snail1 protein facilitates binding of c-Jun to the Snaill promoter. Taken together, Snail1 interaction with c-Jun promotes TGF $\beta$ dependent binding of c-Jun to the Snail1 promoter. In addition, by Chip assays we found that c-Jun binds to the T $\beta R I$ promoter only in the presence of wt-Snaill, but not in the presence of the K234R mutant Snail1, suggesting that K234 is crucial for active gene regulation (Figure $10 \mathrm{~J})$.

\section{Immunohistochemical stainings reveal a correlation between Snail1, Sumo1, T $\beta R I$ and c-Jun expression and malignancy in prostate cancer tissues}

As we have observed that Snaill is critical for EMT regulation in prostate cancer, we performed 
A
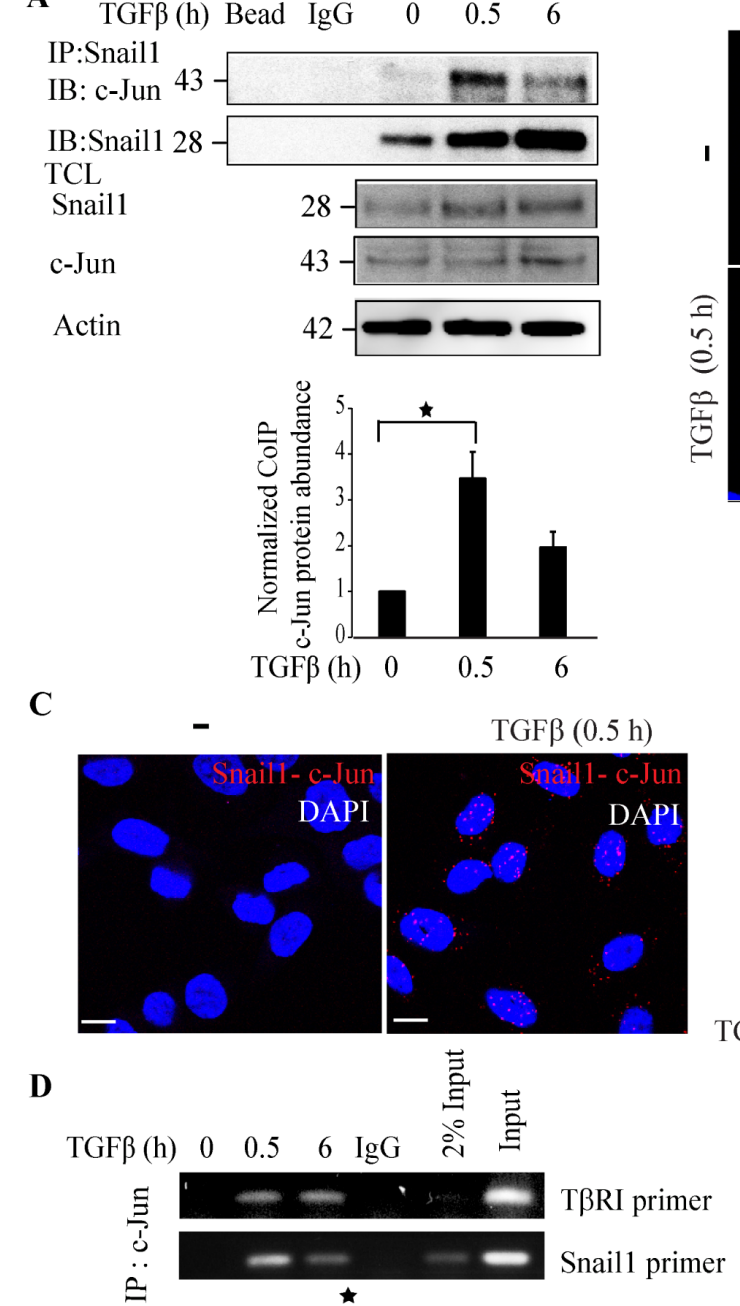

$\mathbf{E}$
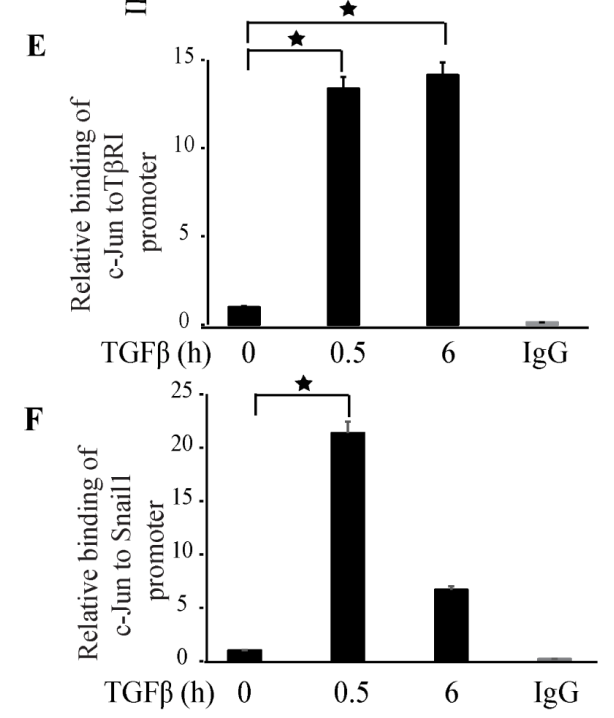

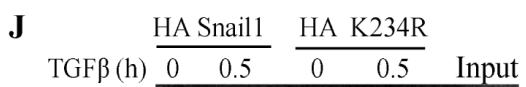

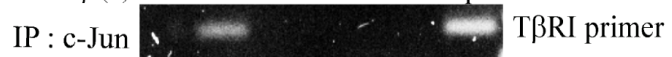

B
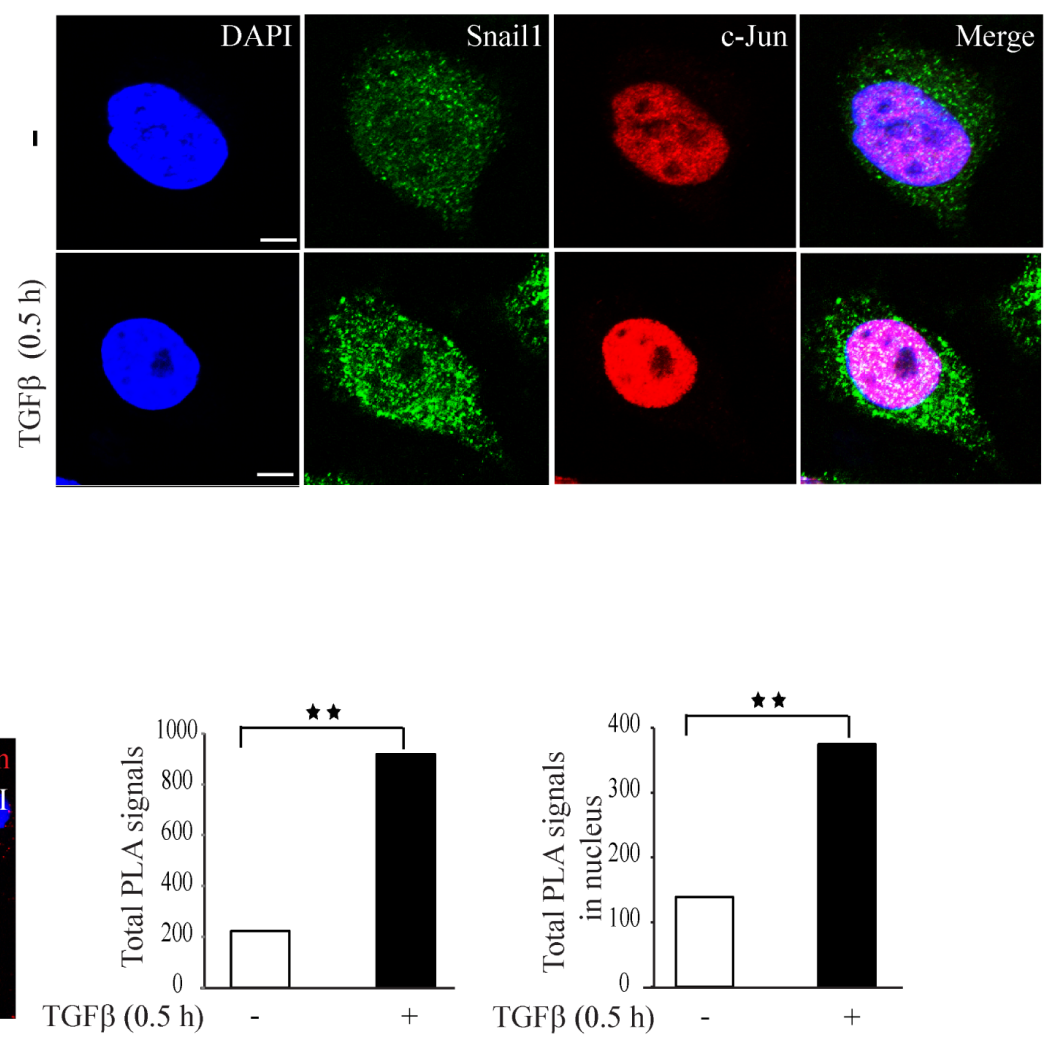

G

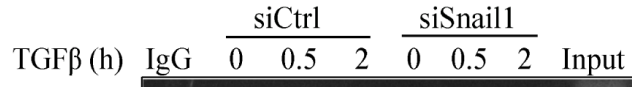

IP : c-Jun Snaill primer

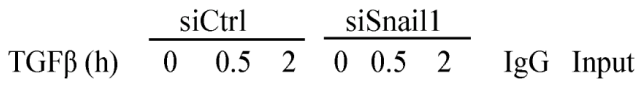

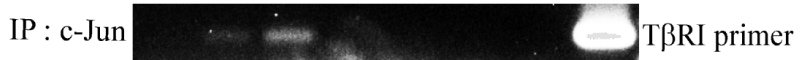

H

Figure 10: TGF $\beta$ promotes Snail1 and c-Jun interaction and co-localisation. A. PC-3U cells were treated with TGF $\beta$ for the indicated time periods. Cell lysates were prepared and immunoprecipitated with goat-Snaill and immunoblotted with rabbit-c-Jun antibodies. Total cell lysates were probed for endogenous Snail1, c-Jun, and $\beta$-actin. ( $n=4$ independent experiments). B. Representative confocal imaging of PC-3U cells treated with TGF $\beta$ for the indicated time periods. Cells were fixed, permeabilised and incubated with anti-rabbit c-Jun and anti-mouse Snaill antibodies, followed by incubation with Alexa Fluor 555 (red) secondary anti-rabbit antibodies and Alexa Fluor 488 (green) secondary anti-mouse antibodies for visualization. Merge of two layers shows co-localization of the proteins. Cell nuclei stained with DAPI. ( $n=3$ independent experiments). C. PLA images of PC-3U cells were treated with TGF $\beta$ for the indicated time periods. Cells were fixed, permeabilised and incubated with anti-rabbit c-Jun and anti-mouse Snaill antibodies, followed by incubation with PLA probes. c-Jun-Snail1 PLA complexes are visualized as red dots. Quantification of c-Jun-Snail1 PLA complexes was done with the aid of Blob finder software. ( $n=3$ independent experiments). D. Chromatin immunoprecipitation (ChIP) assay of c-Jun binding to the T $\beta R I$ and Snail promoters. PC-3U cells treated or not with TGF $\beta$ as indicated and ChIP samples were subjected to agarose gel electrophoresis $(n$ $=5$ independent experiments). E. qRT-PCR analysis of relative binding of c-Jun to T $\beta$ RI promoter. F. qRT-PCR analysis of relative binding of c-Jun to Snaill promoter. G. PC-3U cells transiently transfected with control (Ctrl) or Snaill-specific siRNA \#1 and treated with TGF $\beta$ $(10 \mathrm{ng} / \mathrm{ml})$ for the indicated time periods. ChIP samples were subjected to agarose gel electrophoresis $(n=5$ independent experiments). H. qRT-PCR analysis of relative binding of c-Jun to Snail1 promoter. I. qRT-PCR analysis of relative binding of c-Jun to T $\beta$ RI promoter. J. PC-3U cells transiently transfected with HA-Snaill or Mutant-HA-K234R-Snaill and treated with TGF $\beta$ (10 ng/ml) for the indicated time periods. ChIP samples were subjected to agarose gel electrophoresis to analyze relative binding of c-Jun to T $\beta$ RI promoter $(n=5$ independent experiments). Bar graphs show the means $\pm \mathrm{SEM} ;{ }^{*} P<0.05,{ }^{* *} P<0.005,{ }^{* * *} P<0.0005$. Differences in the means \pm SEM between samples were analyzed with two-way ANOVA and Bonferroni correction for multiple comparisons.

immunohistochemical stainings for Snail1, Sumo1, T $\beta$ RI, Hes1 and c-Jun, in prostate cancer tissues. Increased positive stainings for Snail1, Sumo1, T $\beta$ RI, Hes1, and c-Jun were found in the investigated prostate cancer tissues compared to the normal tissues (Figure $11 \mathrm{~A}-11 \mathrm{~J})$, suggesting that TGF $\beta$-promoted prostate cancer progression, involves increased expression of these EMT promoting factors. No immunohistochemical stainings for Snail1, Sumo1, T $\beta R I$, Hes1 and c-Jun was observed in control experiment when the primary antibodies were omitted) (Supplementary Figure 13A-13E).

\section{DISCUSSION}

The bifunctional role of TGF $\beta$ as a tumor suppressor and tumor promoter is well established $[2,41]$. TGF $\beta$ dictate cellular functional responses by activation of canonical Smad and non-Smad signaling cascades $[1,7$, 16]. Previously, we reported that T $\beta R I$ is cleaved in the ectodomain by TACE and in the transmembrane region by presenilin1 to liberate an T $\beta$ RI-ICD $[20,21,36,42]$. The liberated T $\beta$ RI-ICD translocates to the nucleus where it binds to the Snaill promoter to promote invasion of cancer cells.

Snail1 is a pro-invasive gene regulated by both canonical and non-canonical TGF $\beta$ signaling members [26, 30]. Although Snaill has been reported to be upregulated by TGF $\beta$ to promote EMT, the downstream targets for Snaill are not fully understood and was the topic for our current investigation. In our quest to unravel possible downstream regulators of Snaill, we silenced the expression of Snaill by siRNA and found that T $\beta R I$ expression decreased in the absence of Snail1, suggesting that Snaill regulates T $\beta$ RI expression (Figure 1, Supplementary Figure 1) and that treatment of prostate cancer cells with TGF $\beta$ stimulated formation of Snaill and T $\beta$ RI-ICD complexes in the nucleus of these cancer cells (Figure 2, Supplementary Figures 2 and 4). Snail1 has previously been reported to interact with the R-Smad, Smad3 and co-Smad, Smad4 to drive EMT in breast carcinomas [27]. In this context, Snaill interaction with T $\beta R I$ and regulation of T $\beta R I$ expression, is a novel mechanism identified in this report by which Snaill further enhance TGF $\beta$ signaling and EMT in prostate cancer.

Hes1 is a key transcriptional target in the notch signaling cascade and has also been implicated to play a crucial role in cancer metastasis, and EMT [38, 43, 44] and elevated Jagged 1 expression has been reported in prostate cancer metastasis [45-48]. As we have previously observed that the T $\beta$ RI-ICD forms a complex with the Notch-ICD (NICD) in the nucleus [36], we investigated the possibility if other Notch targets such as Hesl, is regulated by T $\beta$ RIICD. Interestingly, downregulation of Snaill expression caused a decreased Hes1 expression, suggesting that Hes 1 is also regulated by Snaill (Figure 3). Since we observed that Snail1 downregulation decreases both T $\beta$ RI and Hes 1 expression, we also investigated if T $\beta R I$ is the upstream regulator of Hes1. siT $\beta$ RI treatment decreased the expression of Hes1, suggesting that Hes 1 is a T $\beta R I$ target gene (Figure 4) and also other EMT genes (Supplementary Figure 8). TGF $\beta$ treatment induced interaction between Hes 1 and T $\beta$ RI (Figure 5), suggesting that nuclear translocated T $\beta$ RI-ICD interacts with Hes1. Our finding in this report shows that the T $\beta$ RI-ICD interacts with Hes1 and that T $\beta R I$ regulates Hes 1 and Jagged 1 expression. The current data, along with data from our previous study, in which we found that T $\beta$ RI-ICD and NICD interact [36], enhances our knowledge about the common transcriptional targets of the TGF $\beta$ and the Notch signaling cascades $[22,36]$. Moreover, the kinase activity of T $\beta R I$ is crucial for regulating the expression of Hes1 but not for Snail1 expression (Figure 6). As we previously have reported that Snaill expression is independent of T $\beta$ RI kinase activity, Snaill might be regulated by other signaling cascades such 
Normal tissue
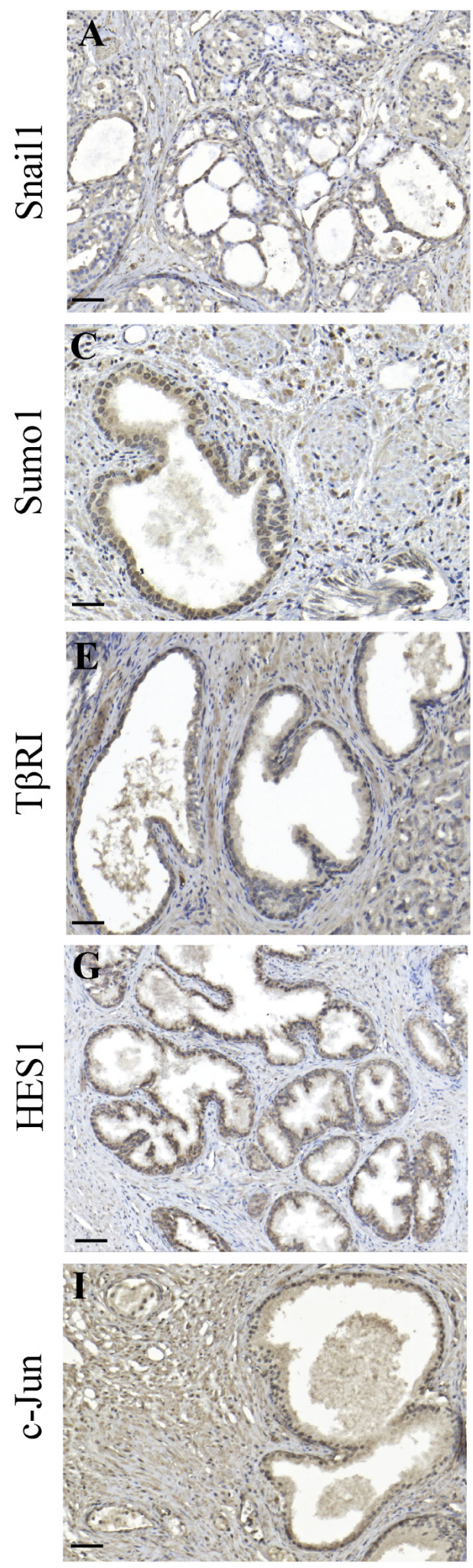

Cancerous tissue
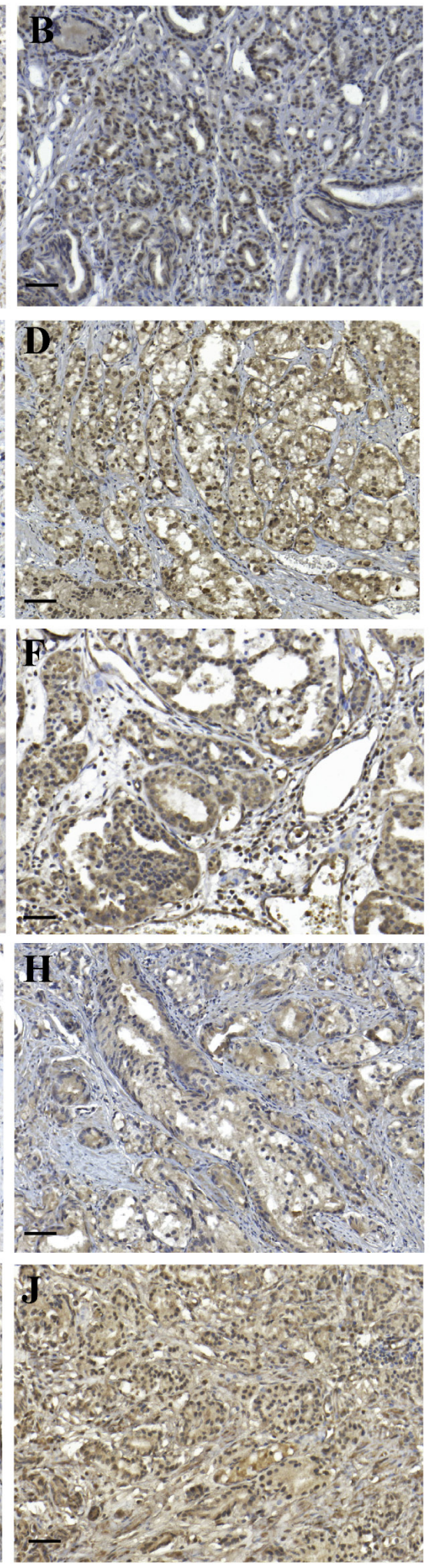

Figure 11: Immunohistochemical staining's for Snail1, Sumo1, T TRI, Hes1, and c-Jun correlates with malignancy of prostate cancer tissues. A.-J. paraffin-embedded sections of prostate cancer tissues were immunostained with Snail1, Sumo1, T $\beta R I$, Hes1, and c-Jun antibodies. 3,3'-Diaminobenzidine was used as chromogen and Mayer hematoxylin as counterstain. Representative images from normal prostate glands (A,C,E,G,I) and cancer tissues (B,D,F,H,J: Scale bar $200 \mu \mathrm{m}$ ). 
as NF-кB, Ras, PI3K/Akt and FGF, as it has been reported that Snail1 promoter consists of transcriptional binding sites for the aforementioned signaling pathway members $[30,31,49]$.

Sumoylation of various proteins has been reported to regulate gene transcription, nuclear transport, and activation of signal transduction pathways [33]. In our study, we have elucidated that TGF $\beta$ stimulates Snaill sumoylation (Figure 7, 8 and Supplementary Figure 10) at lysine 234. Mutation of Snaill at lysine 234 to arginine (K234R) inhibited sumoylation of Snaill, its nuclear translocation, and also the TGF $\beta$-induced migratory and invasive properties in prostate cancer cells (Figure 9), suggesting that sumoylation is important for Snaill function.

Polyubiquitination of Snaill by the ubiquitin ligase FBXL5 has been reported to disrupt its ability to bind to DNA [32]. Moreover, K234 in Snail1 has also been identified as one of the three acceptor lysine residues (K85, K146, K234) for ubiquitination. However K234 is modified upto a very less extent compared to full length Snail1 protein by FBXL5 and the authors also suggested that this ubiquitination modification may not lead to degradation, compared to K146, which is known to be involved in Snaill proteosomal degradation both by $\beta$-TrCP1 and FBXL14, by K48-polyubiquitnation $[32,50]$. Snail1 has a conserved nuclear localization signal (NLS) and is recognized by the importins $(\beta$, $\alpha$ and 7) and transportin for active transport from cytoplasm to the nucleus [51, 52]. Moreover, lysine 234 has been recognized as one among several residues important in Snaill for DNA binding [51]. In this context, sumoylation of Snail1 may be a crucial event for its nuclear translocation, as it could be speculated that this modification may lead to conformational changes in the structure of Sumo1, thereby giving access for importins to bind and promote its nuclear transport.

Snaill has been reported to bind to its own promoter and to regulate its own expression [29]. Previously, we reported that TGF $\beta$ induced transcription of Snaill requires $c$-Jun and $c$-Jun binds to specific distal region of the Snail1 promoter [30, 31]. Immunoprecipitation experiments confirmed that TGF $\beta$ stimulates interaction and co-localization between Snail1 and c-Jun (Figure 10). We report here that $c$-Jun binds to TRRI and Snaill promoter to regulate their expression respectively. Moreover, TGF $\beta$ induced Snaill protein is crucial for c-Jun to bind to T $\beta R I$ and Snaill promoters (Figure 10), suggesting that the Snaill transcription factor might recruit other co-activators such as c-Jun, to bind to T $\beta R I$ or to its own promoter region. Interestingly, only the wt-Snaill promoted $c$-Jun binding to T $\beta$ RI promoter, compared to the Lysine 234 mutant Snail1, to promote transcription of EMT genes, including TRRI and c-Jun (Figure 10, Supplementary Figure 11, 12).

Given that Snaill is a key regulator of the EMT program, we also investigated the mRNA expression profile of other EMT regulator genes, such as Zeb1, Slug, and Twist1. Knockdown of endogenous Snail1 expression decreased expression of all three regulator genes, suggesting that Snail1 is a key inducer of EMT (Supplementary Figure 5D-5F). Moreover, Snail1 enhanced the expression of mesenchymal markers, such as Fibronectin1, $N$-cadherin, and Jagged1 (Supplementary Figure 5A-5C). Taken together, these results suggest that Snaill is the master regulator of EMT, controlling the expression of EMT genes and interestingly, also T $\beta R I$, as demonstrated in this report. Remarkably, knockdown of endogenous T $\beta R \mathrm{R}$ expression decreased expression of Fibronectin1, $\mathrm{N}$-cadherin, and the Notch responsive target Jagged1, the EMT regulator Zeb1 (Supplementary Figure 8A-8D), the classical TGF $\beta$ targets $\operatorname{Smad} 7$ and PAI-1 (Supplementary Figure 8F-8G). Taken together, our data suggest that Snail1-regulated T $\beta R I$ promotes the mesenchymal phenotype and enables the cancer cells to become invasive.

Androgen receptors, which are known to be crucial for prostate cancer tumorigenesis, has been reported to be sumoylated [53-55]. In this context, our data propose that the androgen-independent PC-3U cells, instead utilize sumoylated Snaill to target T $\beta R I$ to promote prostate cancer progression, as we have observed overexpression of Snail1, Sumo1, T $\beta R I$, Hes1, and c-Jun in prostate cancer specimens (Figure 11). These results suggest that Snail1 and Sumo1 might be markers for prostate cancer progression. As sumoylation inhibitors are currently being tested to combat breast cancer tumorigenesis [55], it would be interesting to target Snaill sumoylation to inhibit migration and invasion in prostate cancer, as we in this report identify sumoylated Snaill as a crucial modulator of the EMT program in androgen independent aggressive prostate cancer cells and also in the highly invasive breast cancer (MDA-MB-231) and lung cancer cells (A549).

\section{MATERIALS AND METHODS}

\section{Cell culturing}

Human prostate PC-3U cancer cells, a sub-cell line of PC3, have been previously described [36]. These cells were grown in RPMI-1640 medium supplemented with $10 \%$ fetal bovine serum (FBS), 1\% L-glutamine, and $1 \%$ penicillin and streptomycin. Cells were starved in RPMI-1640 medium supplemented with 1\% FBS, 1\% L-glutamine, and $1 \%$ penicillin and streptomycin. Snail $1^{+/+}$ or Snail1 ${ }^{-/}$mouse embryo fibroblasts (MEFs) were a kind gift from Dr. Antonio García de Herreros, Barcelona), MDA-MB-231, A549 cells were cultured in DMEM medium containing $10 \%$ fetal bovine serum (FBS), $1 \%$ L-glutamine, and $1 \%$ penicillin and streptomycin. 
Cells were starved in DMEM medium containing $0.5 \%$ FBS, $1 \%$ L-glutamine, and $1 \%$ penicillin and streptomycin. After starvation, cells were stimulated with $10 \mathrm{ng} / \mathrm{ml}$ of TGF $\beta 1$ ligand (R\&D Systems), and then harvested by washing with phosphate-buffered saline (PBS) and lysed in RIPA lysis buffer containing $(50 \mathrm{mM}$ Tris (pH 8.0), $150 \mathrm{mM} \mathrm{NaCl}, 1 \%$ Triton X-100, 10\% (v/v) glycerol, $1 \mathrm{mM}$ aprotinin, $1 \mathrm{mM}$ Pefabloc, $1 \mathrm{mM}$ sodium orthovanadate). Protein concentration was measured using the BCA protein assay kit (Nordic Biolabs), and equal amounts of protein were loaded onto sodium dodecyl sulfate-polyacrylamide gel electrophoresis (SDS-PAGE) using gels from Invitrogen. After electrophoresis, proteins were transferred onto a nitrocellulose membrane using an I-blot machine (Invitrogen), blocked in 5\% bovine serum albumin (BSA) and incubated with the respective antibodies.

\section{Antibodies}

Rabbit antisera against HA, p-Smad2, Smad2, Sumo1, Hes1, $\beta$-tubulin, and a mouse monoclonal against HA, were purchased from Cell Signaling; rabbit antisera against T $\beta$ RI (V22) and Snaill-were from Santa Cruz Biotechnology and Novus Biologicals, respectively; a goat antiserum against Snail1, from RnD systems; a mouse antiserum against Hes1 was from Abcam; a mouse antiserum against $\beta$-actin from Sigma Aldrich; and secondary horseradish peroxidase-conjugated goat antirabbit, goat anti-mouse, and anti-goat antibodies were from DAKO. Light-chain specific anti-rabbit, anti-mouse, and anti-goat antibodies were purchased from Jackson Laboratories.

\section{Plasmids}

HA-tagged constitutively active (c.a)T $\beta$ RI (HAT $\beta R I)$ and Flag-tagged c.aT $\beta$ RI was a kind gift from Prof. P. ten Dijke, Leiden. Green fluorescent protein (GFP)tagged c.aT $\beta$ RI (GFP-T $\beta$ RI) was constructed in-house and has been previously described [20]. HA-Snaill was kindly provided by Prof. A. Moustakas, Uppsala. GSTSnaill and HA-Snail1 was provided by Dr. Antonio García de Herreros, Barcelona. HA-Sumo1 was a kind gift from Prof. I. Dikic, Frankfurt.

\section{Transfections}

Transient transfections of ectopically expressed HA-T $\beta$ RI or HA-Snail 1 were performed with FuGENE $®$ 6 transfection reagent (Promega) following the manufacturer's instructions. Transient transfections of small-interfering (si) RNA were performed using Oligofectamine reagent (Invitrogen) following the manufacturer's instructions. siRNA targeting T $\beta R I$, Snail1, or non-targeting control siRNA were purchased from Dharmacon, and Stealth siRNA specific to Snail1 and non-targeting control siRNA were obtained from Invitrogen.

\section{Site-directed mutagenesis}

QuickChange Site-Directed Mutagenesis kit (Agilent Technologies) was used to create a K234R mutant HA-Snaill plasmid, following the manufacturer's instructions. Mutagenesis was confirmed by sequencing of the plasmid.

\section{Luciferase reporter assay}

Transient transfections of small-interfering (si) RNA were performed using Oligofectamine reagent (Invitrogen), following the manufacturer's instructions. Fortyeight hours after siRNA transfection, cells were transiently transfected with $\mathrm{CAGA}_{12}$ reporter and renilla constructs (internal control) with FuGENE® 6 transfection reagent (Promega) following the manufacturer's instructions. After starvation, cells were stimulated with TGF $\beta$ for the indicated time periods. Cells were harvested and lysed in lysis buffer (Promega). Triplicates of each sample were used for measuring the luciferase activity using a luminometer. Values were calculated as follows:

Luciferase activity of sample $=\mathrm{CAGA}_{12}$ reporter activity / renilla reporter activity.

\section{Immunoprecipitation assays and western blotting}

After cells were stimulated for the indicated time periods, they were washed with PBS and lysed in cold RIPA buffer for $20 \mathrm{~min}$ at $4^{\circ} \mathrm{C}$ and centrifuged at 13,000 rpm for $10 \mathrm{~min}$. The supernatant was taken, and the protein concentration was measured with the BCA protein assay kit (Nordic Biolabs) following the manufacturer's instructions. For immunoprecipitation, samples were incubated with primary antibody overnight; the next day, samples were incubated with Protein G Sepharose beads (GE Healthcare) at $4^{\circ} \mathrm{C}$. Samples were washed with RIPA buffer three times and the proteins were extracted from the beads in SDS sample buffer containing reducing agent and heating at $95^{\circ} \mathrm{C}$. Immunoblotting was performed by subjecting equal amount of protein from each treatment group to SDS-PAGE using 10\% or $12 \%$ Bis-tris polyacrylamide gels (Invitrogen). Gels were run in MOPS buffer (Invitrogen), and protein was transferred onto a nitrocellulose membrane using an iBlot Machine (Invitrogen). Quantification of immunoblots were performed with Biorad Quantity one software. Values represent the means of three or more independent 
Table 1: Primers used for qRT-PCR

\begin{tabular}{|l|l|l|}
\hline Gene name & Forward primer & Reverse primer \\
\hline Snail1 & GAAAGGCCTTCAACTGCAAA & TGACATCTGAGTGGGTCTGG \\
\hline T $\beta$ I & TGTTGGTACCCAAGGAAAGC & CACTCTGTGGTTTGGAGCAA \\
\hline Smad7 & TCCTGCTGTGCAAAGTGTTC & TCTGGACAGTCTGCAGTTGG \\
\hline PAI-1 & CTCTCTCTGCCCTCACCAAC & GTGGAGAGGCTCTTGGTCTG \\
\hline Hes 1 & TGAAGAAAGATAGCTCGCGG & GGTACTTCCCCAGCACACTT \\
\hline Twist1 & TTCTCGGTCTGGAGGATGGA & CCCACGCCCTGTTTCTTTGAA \\
\hline Fibronectin1 & CCGTGGGCAACTCTGTC & TGCGGCAGTTGTCACAG \\
\hline N-Cadherin & CGGCCCGCTATTTGTCATCA & TGCGATTTCACCAGAAGCCT \\
\hline Jagged1 & GATGATGGGAACCCGATCAA & GCAAGGGAACAAGGAAATCTGT \\
\hline Zeb1 & GCAGGTGAGCAACTGGGAAA & ACAAGACACCGCCGTCATTT \\
\hline Slug & TGTTGCAGTGAGGGCAAGAA & GACCCTGGTTGCTTCAAGGA \\
\hline GAPDH & TGATGACATCAAGAAGGTGGTGAAG & TCCTTGGAGGCCATGTGGGCCAT \\
\hline
\end{tabular}

biological experiments. Bars are presented as means \pm SEM and statistical analysis was based on at least three independent biological experiments. Differences in the means \pm SEM between samples were analyzed with twoway ANOVA with bonferroni post hoc test using SPSS software.

\section{Immunofluorescence and confocal microscopy}

PC-3U cells were cultured in six-well dishes in the presence of RPMI-1640 medium supplemented with $10 \% \mathrm{FBS}, 1 \%$ L-glutamine, and $1 \%$ penicillin and streptomycin. Cells were transfected with the respective plasmids; after $24 \mathrm{~h}$, cells were starved in RPMI-1640 medium supplemented with 1\% FBS, 1\% L-glutamine, and $1 \%$ penicillin and streptomycin, and after an additional $18 \mathrm{~h}$, cells were stimulated with $10 \mathrm{ng} / \mathrm{ml}$ of TGF $\beta 1$.

Cells were washed in PBS and fixed in $4 \%$ paraformaldehyde, followed by permeabilization in $2 \%$ Triton X-100. Cells were blocked in 5\% BSA. After blocking, cells were incubated with primary antibody for $1 \mathrm{~h}$, followed by incubation with secondary donkey anti-rabbit Alexa Fluor 555 antibodies or goat anti-mouse Alexa Fluor 488 antibodies (Invitrogen). After staining, cells were mounted in medium with 4',6-diamidino-2phenylindole (DAPI) to visualize cell nuclei. Images were taken with a confocal microscope with an oil immersion $63 \mathrm{X}$ lens. Zen software was used to analyze the data.

\section{Proximity Ligation Assay (PLA)}

PC-3U cells, untreated or treated with TGF $\beta$, were fixed, permeabilized, blocked and probed with the primary antibodies as indicated, following the manufacturers protocol. Antibodies from different species against T $\beta$ RI (V22), Snail1, Hes1, Sumo1 and c-Jun, were used. Next, the cells were incubated with PLA probes (Sigma-
Aldrich), followed by ligation and amplification. Slides were mounted with Duolink mounting medium and evaluated with a confocal microscope (Carl Zeiss). Images were acquired with a $63 \mathrm{X}$ objective. Representative results are shown from experiments repeated at least three times. Cell images were exported in TIF format with Zen software (Carl Zeiss) for further analysis; quantification of PLA signals were determined with Blob-Finder image analysis software, which was developed by the Center for Image Analysis, Uppsala University, Sweden.

\section{RNA isolation, cDNA synthesis, and RT-PCR}

RNA isolation was performed using the RNeasy Mini Kit (Qiagen), following the manufacturer's instructions. A total of $2 \mu \mathrm{g}$ of RNA was used for cDNA synthesis using the Thermoscript cDNA synthesis kit (Invitrogen). qRT-PCR was performed using the Power SYBR Green Master Mix (Applied Biosystems). Samples were run on an Applied Biosystems 7900HT Fast RealTime PCR system (Table 1).

\section{Chip assay}

Chromatin immunoprecipitation (ChIP) assay was performed using the SimpleChIP $®$ Plus Enzymatic Chromatin IP Kit from Cell Signaling Technology following the manufacturer's protocol. DNA and proteins were cross-linked in 4\% formaldehyde. After shearing of the cells the chromatin was precipitated using c-Jun ChIP grade antibody, and reverse crosslinked. After purification, DNA was amplified using standard PCR and run on 1.5\% agarose gel or subjected to quantitative RT-PCR with the Power SYBR PCR Master Mix.

The following ChIP primers were used (Table 2). 
Table 2: ChIP primers

\begin{tabular}{|l|l|l|}
\hline Gene name & Forward primer & Reverse primer \\
\hline c-Jun & AAGCACACTTCCCTTTGCAT & GGACAGAACACTCAGAGCCT \\
\hline T $\beta$ RI & TGGAGCGTCTCGCAGTAAAT & CCCTTCTTAGCACCCAGCTC \\
\hline
\end{tabular}

\section{In vitro sumoylation assay}

His-Snail1 (RnD Systems) and GST-RanGAP1 (Enzo Life Sciences) were used as substrates in in vitro sumoylation assays, assays were performed following the instructions provided by the manufacturer (Enzo Life Sciences). His-Snail or GST-RanGAP1 (positive control) were incubated with Sumo E1 (Aos1 and Uba2), E2 (Ubc9), E3 Sumo1 or E3 Sumo2 enzymes in the presence or absence of Mg-ATP in sumoylation buffer for $1 \mathrm{~h}$ at $37^{\circ} \mathrm{C}$. The reactions were quenched by adding SDS sample buffer and heating at $95^{\circ} \mathrm{C}$ for $5 \mathrm{~min}$. The reaction mixture was analyzed by immunoblotting using anti-Sumo1, antiSumo2 and anti-Snaill antibodies.

\section{In vivo sumoylation assay}

PC-3U, MDA-MB-231, A549 cells were transfected with HA-Sumo1 or non-transfected cells, were stimulated with TGF $\beta$ for the indicated time periods [37], then harvested and washed in PBS. Cells were pelleted by centrifugation and incubated with 1\% SDS, followed by heating at $95^{\circ} \mathrm{C}$ for $10 \mathrm{~min}$. PBS containing $0.5 \%$ NP40 and proteinase inhibitors was added, followed by centrifugation at $13,000 \mathrm{rpm}$ for $10 \mathrm{~min}$. The supernatant was transferred to a new tube discarding the slimy layer, and immunoprecipitated with Snaill antibodies, and analyzed by immunoblotting using anti-Sumol and antiHA antibodies.

\section{Wound healing assays}

Scratch wound healing assays using PC-3U cells were performed in 6-well plates. Cells were transfected with either wt-Snail1 or mutant-Snail1. Cells were serumstarved prior to creating an approximately $0.6 \mathrm{~mm}$ wide wound using a pipette tip. Thereafter, cells were stimulated with TGF $\beta$ for $24 \mathrm{~h}$. Images were taken by a microscope with a digital camera, using QED software.

\section{Invasion assay}

Invasion assays were performed using Corning BioCoat Growth Factor (GFR) reduced Matrigel Invasion Chamber, following the manufacturer's instructions. Serum-free RPMI-1640 was used to rehydrate the GFR Matrigel inserts. Cells were seeded into the insert in RPMI-1640 medium with $1 \%$ FBS, with or without
TGF $\beta 1$. The lower chamber was filled with RPMI 1640 with $10 \%$ FBS. After $24 \mathrm{~h}$ of incubation in a humidified tissue culture incubator, non-invasive cells were scrubbed off the upper surface of the membrane. The remaining invasive cells were stained with crystal violet staining solution and then photographed. Colorimetric quantification was performed by measuring the optical density at $560 \mathrm{~nm}$ using a spectrophotometer.

\section{Immunohistochemistry}

Paraffin embedded tissue sections from patients with prostate cancer, were deparaffinised and tissue sections were prepared according to the manufacturer's instructions (Thermoscientific). Primary antibodies against Snaill, Sumo1, T $\beta R I$, Hes1 and c-Jun were used for staining. $\mathrm{DAB}$ chromogen (brown color) was used for the detection and the sections were counterstained with hematoxylin to visualize nuclei (blue). The stained tissues were dried overnight and then scanned with Panoramic 250 Flash scanner (3D HISTECH Ltd). Ethical permit to use tumor tissues for generation of tissue slides was provided by the Umeå University. Ethical review board in full agreement with the Swedish Ethical Review Act (540/03, Dnr 03482).

\section{Statistical analysis of qRT-PCR data}

After qRT-PCR, the cycle threshold $\left(\mathrm{C}_{\mathrm{T}}\right)$ values of respective genes were normalized to the $\mathrm{C}_{\mathrm{T}}$ of the reference gene $G A P D H$. Then, the $\Delta \mathrm{C}_{\mathrm{T}}$ values were obtained and plotted. We performed statistical analysis for each of three or more independent qRT-PCR assays. Bars are presented as means \pm SEM from at least three independent experiments. Differences in the means \pm SEM between samples were analyzed with two-way ANOVA with bonferroni post hoc test using SPSS software.

\section{ACKNOWLEDGMENTS}

We are greatful for the possibility to use Snail1 ${ }^{+/+}$ or Snail1 ${ }^{-}$mouse embryo fibroblasts (MEFs) in our study, which were a kind gift from Dr. Antonio García de Herreros, Barcelona), Spain.

\section{CONFLICTS OF INTEREST}

The authors declare no conflicts of interest. 


\section{GRANT SUPPORT}

This work was supported by grants to ML from the Swedish Medical Research Council (K2016-02513), the Swedish Cancer Society (CAN 2014/674), ALFVLL-464591 and ALF-VLL-583901, the Knut and Alice Wallenberg Foundation (2012.0090), the Cancer Research Foundation in Northern Sweden, Lion's Cancer Research Foundation, and Umeå University.

\section{REFERENCES}

1. Massague J. TGFbeta signalling in context. Nat Rev Mol Cell Biol. 2012; 13: 616-30. doi: 10.1038/nrm3434.

2. Heldin $\mathrm{CH}$, Landstrom $\mathrm{M}$, Moustakas A. Mechanism of TGF-beta signaling to growth arrest, apoptosis, and epithelial-mesenchymal transition. Curr Opin Cell Biol. 2009; 21: 166-76. doi: 10.1016/j.ceb.2009.01.021.

3. Roberts AB, Lamb LC, Newton DL, Sporn MB, De Larco JE, Todaro GJ. Transforming growth factors: isolation of polypeptides from virally and chemically transformed cells by acid/ethanol extraction. Proc Natl Acad Sci U S A. 1980; 77: 3494-8.

4. Moses HL, Branum EL, Proper JA, Robinson RA. Transforming growth factor production by chemically transformed cells. Cancer Res. 1981; 41: 2842-8.

5. Massague J. TGFbeta in Cancer. Cell. 2008; 134: 215-30. doi: 10.1016/j.cell.2008.07.001.

6. Padua D, Massagué J. Roles of TGFbeta in metastasis. Cell Res. 2009; 19: 89-102. doi: 10.1038/cr.2008.316.

7. $\mathrm{Mu}$ Y, Gudey SK, Landstrom M. Non-Smad signaling pathways. Cell Tissue Res. 2012; 347: 11-20. doi: 10.1007/ s00441-011-1201-y.

8. Heldin $\mathrm{CH}$, Vanlandewijck M, Moustakas A. Regulation of EMT by TGFbeta in cancer. FEBS Lett. 2012; 586: 195970. doi: 10.1016/j.febslet.2012.02.037.

9. Wrana JL, Attisano L, Wieser R, Ventura F, Massague J. Mechanism of activation of the TGF-beta receptor. Nature. 1994; 370: 341-7. doi: 10.1038/370341a0.

10. Souchelnytskyi S, Tamaki K, Engstrom U, Wernstedt C, ten Dijke P, Heldin CH. Phosphorylation of Ser465 and Ser467 in the C terminus of Smad2 mediates interaction with Smad4 and is required for transforming growth factorbeta signaling. J Biol Chem. 1997; 272: 28107-15.

11. Abdollah S, Macias-Silva M, Tsukazaki T, Hayashi H, Attisano L, Wrana JL. TbetaRI phosphorylation of Smad2 on Ser465 and Ser467 is required for Smad2-Smad4 complex formation and signaling. J Biol Chem. 1997; 272: 27678-85.

12. Macias-Silva M, Abdollah S, Hoodless PA, Pirone R, Attisano L, Wrana JL. MADR2 is a substrate of the TGFbeta receptor and its phosphorylation is required for nuclear accumulation and signaling. Cell. 1996; 87: 121524.
13. Ross $\mathrm{S}$, Hill CS. How the Smads regulate transcription. Int J Biochem Cell Biol. 2008; 40: 383-408. doi: 10.1016/j. biocel.2007.09.006.

14. Jonk LJ, Itoh $\mathrm{S}$, Heldin $\mathrm{CH}$, ten Dijke $\mathrm{P}$, Kruijer W. Identification and functional characterization of a Smad binding element (SBE) in the JunB promoter that acts as a transforming growth factor-beta, activin, and bone morphogenetic protein-inducible enhancer. J Biol Chem. 1998; 273: 21145-52.

15. Moustakas A, Heldin CH. Non-Smad TGF-beta signals. J Cell Sci. 2005; 118: 3573-84. doi: 10.1242/jcs.02554.

16. Derynck R, Zhang YE. Smad-dependent and Smadindependent pathways in TGF-beta family signalling. Nature. 2003; 425: 577-84. doi: 10.1038/nature02006.

17. Sorrentino A, Thakur N, Grimsby S, Marcusson A, von Bulow V, Schuster N, Zhang S, Heldin CH, Landstrom M. The type I TGF-beta receptor engages TRAF6 to activate TAK1 in a receptor kinase-independent manner. Nat Cell Biol. 2008; 10: 1199-207. doi: 10.1038/ncb1780.

18. Yamashita M, Fatyol K, Jin C, Wang X, Liu Z, Zhang YE. TRAF6 mediates Smad-independent activation of JNK and p38 by TGF-beta. Mol Cell. 2008; 31: 918-24. doi: 10.1016/j.molcel.2008.09.002.

19. Thakur N, Sorrentino A, Heldin CH, Landstrom M. TGFbeta uses the E3-ligase TRAF6 to turn on the kinase TAK1 to kill prostate cancer cells. Future Oncol. 2009; 5: 1-3. doi: 10.2217/14796694.5.1.1.

20. Mu Y, Sundar R, Thakur N, Ekman M, Gudey SK, Yakymovych M, Hermansson A, Dimitriou H, BengoecheaAlonso MT, Ericsson J, Heldin CH, Landstrom M. TRAF6 ubiquitinates TGFbeta type I receptor to promote its cleavage and nuclear translocation in cancer. Nat Commun. 2011; 2: 330. doi: 10.1038/ncomms1332.

21. Sundar R, Gudey SK, Heldin CH, Landstrom M. TRAF6 promotes TGFbeta-induced invasion and cell-cycle regulation via Lys63-linked polyubiquitination of Lys178 in TGFbeta type I receptor. Cell Cycle. 2015; 14: 554-65. doi: 10.4161/15384101.2014.990302.

22. Gudey SK, Wallenius A, Landstrom M. Regulated intramembrane proteolysis of the TGFbeta type I receptor conveys oncogenic signals. Future Oncol. 2014. doi: 10.2217/fon.14.45.

23. Kalluri R, Weinberg RA. The basics of epithelialmesenchymal transition. J Clin Invest. 2009; 119: 1420-8. doi: 10.1172/JCI39104.

24. Thiery JP, Acloque H, Huang RY, Nieto MA. Epithelialmesenchymal transitions in development and disease. Cell. 2009; 139: 871-90. doi: 10.1016/j.cell.2009.11.007.

25. Yoshino J, Monkawa T, Tsuji M, Inukai M, Itoh H, Hayashi M. Snail1 is involved in the renal epithelial-mesenchymal transition. Biochem Biophys Res Commun. 2007; 362: 638. doi: 10.1016/j.bbrc.2007.07.146.

26. Peinado H, Quintanilla M, Cano A. Transforming growth factor beta-1 induces snail transcription factor in epithelial 
cell lines: mechanisms for epithelial mesenchymal transitions. J Biol Chem. 2003; 278: 21113-23. doi: 10.1074/jbc.M211304200.

27. Vincent T, Neve EP, Johnson JR, Kukalev A, Rojo F, Albanell J, Pietras K, Virtanen I, Philipson L, Leopold PL, Crystal RG, de Herreros AG, Moustakas A, et al. A SNAIL1-SMAD3/4 transcriptional repressor complex promotes TGF-beta mediated epithelial-mesenchymal transition. Nat Cell Biol. 2009; 11: 943-50. doi: 10.1038/ ncb1905.

28. Thuault S, Tan EJ, Peinado $\mathrm{H}$, Cano A, Heldin $\mathrm{CH}$, Moustakas A. HMGA2 and Smads co-regulate SNAIL1 expression during induction of epithelial-to-mesenchymal transition. J Biol Chem. 2008; 283: 33437-46. doi: 10.1074/ jbc.M802016200.

29. Peiro S, Escriva M, Puig I, Barbera MJ, Dave N, Herranz N, Larriba MJ, Takkunen M, Franci C, Munoz A, Virtanen I, Baulida J, Garcia de Herreros A. Snaill transcriptional repressor binds to its own promoter and controls its expression. Nucleic Acids Res. 2006; 34: 2077-84. doi: 10.1093/nar/gk1141.

30. Thakur N, Gudey SK, Marcusson A, Fu JY, Bergh A, Heldin $\mathrm{CH}$, Landstrom M. TGFbeta-induced invasion of prostate cancer cells is promoted by c-Jun-dependent transcriptional activation of Snail1. Cell Cycle. 2014; 13: 2400-14. doi: 10.4161/cc.29339.

31. Garcia de Herreros A, Moustakas A. Invasive cells follow Snail's slow and persistent pace. Cell Cycle. 2014; 13: 2320-1. doi: 10.4161/cc.29831.

32. Vinas-Castells R, Frias A, Robles-Lanuza E, Zhang K, Longmore GD, Garcia de Herreros A, Diaz VM. Nuclear ubiquitination by FBXL5 modulates Snail1 DNA binding and stability. Nucleic Acids Res. 2014; 42: 1079-94. doi: 10.1093/nar/gkt935.

33. Johnson ES. Protein modification by SUMO. Annu Rev Biochem. 2004; 73: 355-82. doi: 10.1146/annurev. biochem.73.011303.074118.

34. Bekes M, Prudden J, Srikumar T, Raught B, Boddy MN, Salvesen GS. The dynamics and mechanism of SUMO chain deconjugation by SUMO-specific proteases. J Biol Chem. 2011; 286: 10238-47. doi: 10.1074/jbc. M110.205153.

35. Eisenhardt N, Chaugule VK, Koidl S, Droescher M, Dogan E, Rettich J, Sutinen P, Imanishi SY, Hofmann K, Palvimo JJ, Pichler A. A new vertebrate SUMO enzyme family reveals insights into SUMO-chain assembly. Nat Struct Mol Biol. 2015; 22: 959-67. doi: 10.1038/nsmb.3114.

36. Gudey SK, Sundar R, Mu Y, Wallenius A, Zang G, Bergh A, Heldin $\mathrm{CH}$, Landstrom M. TRAF6 Stimulates the Tumor-Promoting Effects of TGFbeta Type I Receptor Through Polyubiquitination and Activation of Presenilin 1. Sci Signal. 2014; 7: ra2. doi: 10.1126/scisignal.2004207.

37. Hilgarth RS, Sarge KD. Detection of sumoylated proteins. Methods Mol Biol. 2005; 301: 329-38. doi: 10.1385/1-
59259-895-1:329.

38. Liu ZH, Dai XM, Du B. Hes1: a key role in stemness, metastasis and multidrug resistance. Cancer Biol Ther. 2015; 16: 353-9. doi: 10.1080/15384047.2015.1016662.

39. Lamouille S, Xu J, Derynck R. Molecular mechanisms of epithelial-mesenchymal transition. Nat Rev Mol Cell Biol. 2014; 15: 178-96. doi: 10.1038/nrm3758.

40. Wang Y, Shi J, Chai K, Ying X, Zhou BP. The Role of Snail in EMT and Tumorigenesis. Curr Cancer Drug Targets. 2013; 13: 963-72.

41. Massagué J. TGF-beta signal transduction. Annu Rev Biochem. 1998; 67:753-91.

42. Sitaram RT, Mallikarjuna P, Landstrom M, Ljungberg B. Transforming growth factor-beta promotes aggressiveness and invasion of clear cell renal cell carcinoma. Oncotarget. 2016; 7: 35917-31. doi: 10.18632/oncotarget.9177.

43. Capaccione KM, Pine SR. The Notch signaling pathway as a mediator of tumor survival. Carcinogenesis. 2013; 34: 1420-30. doi: 10.1093/carcin/bgt127.

44. Liu Z, Fu Q, Fu H, Wang Z, Xu L, An H, Li Y, Xu J. A three-molecule score based on Notch pathway predicts poor prognosis in non-metastasis clear cell renal cell carcinoma. Oncotarget. 2016; 7: 68559-70. doi: 10.18632/ oncotarget.11849.

45. Santagata S, Demichelis F, Riva A, Varambally S, Hofer MD, Kutok JL, Kim R, Tang J, Montie JE, Chinnaiyan AM, Rubin MA, Aster JC. JAGGED1 expression is associated with prostate cancer metastasis and recurrence. Cancer Res. 2004; 64: 6854-7. doi: 10.1158/0008-5472.CAN-04-2500.

46. Kwon OJ, Valdez JM, Zhang L, Zhang B, Wei X, Su Q, Ittmann MM, Creighton CJ, Xin L. Increased Notch signalling inhibits anoikis and stimulates proliferation of prostate luminal epithelial cells. Nat Commun. 2014; 5: 4416. doi: 10.1038/ncomms5416.

47. Sethi N, Dai X, Winter CG, Kang Y. Tumor-derived JAGGED1 promotes osteolytic bone metastasis of breast cancer by engaging notch signaling in bone cells. Cancer Cell. 2011; 19: 192-205. doi: 10.1016/j.ccr.2010.12.022.

48. Zhu H, Zhou X, Redfield S, Lewin J, Miele L. Elevated Jagged-1 and Notch-1 expression in high grade and metastatic prostate cancers. Am J Transl Res. 2013; 5: 36878.

49. Kaufhold S, Bonavida B. Central role of Snaill in the regulation of EMT and resistance in cancer: a target for therapeutic intervention. J Exp Clin Cancer Res. 2014; 33 : 62. doi: 10.1186/s13046-014-0062-0.

50. Vinas-Castells R, Beltran M, Valls G, Gomez I, Garcia JM, Montserrat-Sentis B, Baulida J, Bonilla F, de Herreros AG, Diaz VM. The hypoxia-controlled FBXL14 ubiquitin ligase targets SNAIL1 for proteasome degradation. J Biol Chem. 2010; 285: 3794-805. doi: 10.1074/jbc.M109.065995.

51. Mingot JM, Vega S, Maestro B, Sanz JM, Nieto MA. Characterization of Snail nuclear import pathways as representatives of $\mathrm{C} 2 \mathrm{H} 2$ zinc finger transcription factors. J 
Cell Sci. 2009; 122: 1452-60. doi: 10.1242/jcs.041749.

52. Yamasaki H, Sekimoto T, Ohkubo T, Douchi T, Nagata Y, Ozawa M, Yoneda Y. Zinc finger domain of Snail functions as a nuclear localization signal for importin beta-mediated nuclear import pathway. Genes Cells. 2005; 10: 455-64. doi: 10.1111/j.1365-2443.2005.00850.x.

53. Rytinki M, Kaikkonen S, Sutinen P, Paakinaho V, Rahkama V, Palvimo JJ. Dynamic SUMOylation is linked to the activity cycles of androgen receptor in the cell nucleus. Mol Cell Biol. 2012; 32: 4195-205. doi: 10.1128/MCB.0075312.
54. Poukka H, Karvonen U, Janne OA, Palvimo JJ. Covalent modification of the androgen receptor by small ubiquitinlike modifier 1 (SUMO-1). Proc Natl Acad Sci U S A. 2000; 97: 14145-50. doi: 10.1073/pnas.97.26.14145.

55. Bogachek MV, Park JM, Andrade JP, Kulak MV, White JR, Wu T, Spanheimer PM, Woodfield GW, Bair TB, Olivier AK, Weigel RJ. SUMO Inhibitors affect tumorigenesis of novel breast cancer xenograft model. Cancer Res. 2015; 75:Abstract nr P6-02-03. 